\title{
The Role of Racial Discrimination on Parental Emotion and Racial Socialization
}

Tyia K. Wilson

tw0013@mix.wvu.edu

Follow this and additional works at: https://researchrepository.wvu.edu/etd

Part of the Developmental Psychology Commons, and the Multicultural Psychology Commons

\section{Recommended Citation}

Wilson, Tyia K., "The Role of Racial Discrimination on Parental Emotion and Racial Socialization" (2020). Graduate Theses, Dissertations, and Problem Reports. 7764.

https://researchrepository.wvu.edu/etd/7764

This Dissertation is protected by copyright and/or related rights. It has been brought to you by the The Research Repository @ WVU with permission from the rights-holder(s). You are free to use this Dissertation in any way that is permitted by the copyright and related rights legislation that applies to your use. For other uses you must obtain permission from the rights-holder(s) directly, unless additional rights are indicated by a Creative Commons license in the record and/ or on the work itself. This Dissertation has been accepted for inclusion in WVU Graduate Theses, Dissertations, and Problem Reports collection by an authorized administrator of The Research Repository @ WVU.

For more information, please contact researchrepository@mail.wvu.edu. 
The Role of Racial Discrimination on Parental Emotion and Racial Socialization

Tyia Wilson, M.S.

\author{
Dissertation submitted to the \\ Eberly College of Arts and Sciences \\ at West Virginia University \\ in partial fulfillment of the requirements \\ for the degree of
}

Doctor of Philosophy in Psychology
Amy Gentzler, Ph.D. Chair Aaron Metzger, Ph.D. Amy Root, Ph.D.
Heather Washington, Ph.D.

Department of Psychology

Morgantown, West Virginia 2020

Keywords: African American, parenting, emotion socialization, racial socialization, emotional beliefs

Copyright 2020 Tyia Wilson 


\begin{abstract}
The Role of Racial Discrimination on Parental Emotion and Racial Socialization Tyia Wilson
\end{abstract}

This study was the first to examine whether African American parents' past experiences with racism and discrimination influence parents' emotional and racial socialization practices. Additionally, this study investigated whether parental beliefs about their child's positive and negative emotions mediated the relationship between racial discrimination and emotion socialization behaviors. Hypotheses were tested in a sample of 406 African American parents recruited through Amazon Mechanical Turk (MTurk). Using structural equation models, the study found significant association between racial discrimination and parents' racial and emotion socialization behaviors. Furthermore, significant meditation effects were found such that racial discrimination was associated with emotional beliefs which predicted emotion socialization behaviors. This study adds to the literature by investigating differences within an African American sample of parents, given that the majority of research on parenting and socialization has either included samples of limited diversity (e.g., mostly White parents) or has compared parenting across racial groups (e.g., Black vs. White parents). This study provides novel information on how and why there may be variation in parenting within African Americans due to their experiences with racial discrimination. 


\section{TABLE OF CONTENTS}

I. Abstract (ppii)

II. Introduction (pp1-17)

III. Methods (pp17-25)
a. Participants (pp18)
b. Procedure (pp19)
c. Measures (pp20-25)

IV. Results (pp25-35)
a. Preliminary analyses (pp25-26)
b. Primary analyses (pp26-35)

V. Discussion (pp35-50)

VI. References (pp51-69)

VII. Table 1: Participants' Demographic Information (pp70-71)

VIII. Table 2: Descriptive Statistics of Main Variables (pp72)

IX. Table 3: Bivariate Correlations among Demographic and Main Variables (pp73)

X. Table 4: Bivariate Correlations among Demographic and Control Variables (pp74)

XI. Table 5: Bivariate Correlation among Main Variables of Interest (pp75)

XII. Table 6: Bivariate Correlations among Racial Discrimination, Emotional Beliefs, and Emotion Socialization (pp76)

XIII. Table 7: Unstandardized Estimates and Standard Errors of Structural Model Testing Associations among Covariates, Racial Discrimination, PA Beliefs, and PA Socialization $(\mathrm{pp} 77)$ 
XIV. Table 8: Unstandardized Estimates and Standard Errors of Structural Model Testing Associations among Covariates, Racial Discrimination, NA Beliefs, and NA Socialization $(\mathrm{pp} 78)$

XV. Figure 1: Dunbar and colleagues (2017) combined model of racial/ethnic and emotion socialization (pp79)

XVI. Figure 2: Eisenberg, Spinrad, and Cumberland's heuristic model of emotion socialization (pp80)

XVII. Figure 3: Participant deletion (pp81)

XVIII. Figure 4: Proposed model using structural equation modeling (pp82)

XIX. Figure 5: Positive Emotions Measurement Model (pp83)

XX. Figure 6: Positive Emotions Structural Model (pp84)

XXI. Figure 7: Negative Emotions Measurement Model (pp85)

XXII. Figure 8: Negative Emotions Structural Model (pp86)

XXIII. Figure 9: Racial Discrimination Predicting Racial Socialization Behaviors Structural Model (pp87) 
The Role of Racial Discrimination on Parental Emotion and Racial Socialization

Parenting behaviors can depend on various factors such as the parent's personality, work, martial relations, and child characteristics (Belsky, 1984). One important factor that can affect parenting behaviors, which has been largely overlooked, is one's experience with racial discrimination. The majority of parenting research and theories are based on limited samples that lack diversity (e.g., predominantly White). There is a growing body of research on the parenting behaviors of African Americans, but there is still limited research that examines how parents' experiences with racial discrimination may influence African Americans' parenting. The present study examined whether experiences with racial discrimination are related to parental emotion socialization (i.e., modeling emotion regulation, discussing emotion and reacting to their child's expression of emotions) and racial socialization (i.e., how parents may teach their child about their race and culture and how to cope with adversities related to racial disparities) behaviors. Additionally, previous research has shown that parents' emotional beliefs influence parenting behaviors such as emotion socialization (e.g., Eisenberg, Cumberland, \& Spinrad, 1998; Gottman, Katz, \& Hooven, 1997), and this study furthers the literature by examining African American parents' emotional beliefs as a mediating agent between experiences with racial discrimination and emotion socialization behaviors. The present study can help researchers better understand the effects of racial discrimination on African American parenting and provide further explanation of African American parents' motives behind racial and emotional socialization behaviors. Because discrimination is a known stressor for African Americans (Clark, Anderson, Clark, \& Williams, 1999), determining if these experiences negatively impacts parenting can aid in the development of interventions to help parents who have experienced discrimination, and ultimately help their children. 


\section{Racial Discrimination Against African Americans}

Due to African Americans' past history of enslavement, African Americans continue to experience racism and discrimination today. Racial discrimination can be defined as the unfair or unjust treatment of an individual based on their race or skin color (Jackson et al., 1998).

Discrimination is the most prominent stressor in African Americans' everyday lives (Clark, Anderson, Clark, \& Williams, 1999) and leads to a host of detrimental outcomes. African Americans who experience discrimination have reported low levels of well-being (Deitch et al., 2003), greater anger expression (Brondolo et al., 2009; Utsey et al., 2000), higher depressive symptoms (Hudson, Neighbors, Geronimus, \& Jackson, 2016; Sellers et al., 2006; Wong et al 2003), and increased levels of perceived stress (Sellers et al., 2006). Discrimination has also been linked to poorer health outcomes such as increased blood pressure (Goosby, Malone, Richardson, Cheadle, \& Williams, 2015; Krieger \& Sidney, 2016; Lewis et al., 2009), high inflammatory markers in children (Goosby et al. 2015) and older adults (Lewis et al., 2011), high visceral fat (Lewis et al., 2011), and even mortality (Barnes et al., 2008; Williams, Neighbors, \& Jackson, 2003). The saliency of racial discrimination in African Americans' lives forces African Americans to adapt their lifestyle and parenting.

\section{Racial Socialization}

Due to the discriminatory environment that African Americans live in, African Americans tend to engage in various racial socialization strategies in an attempt to reduce the possible negative effects their child will encounter from discrimination. The triple quandary theory is a racial socialization framework that describes the need for African American families to simultaneously and effectively manage three different social contexts at once: the Black/African American cultural experience, the mainstream, and being a member of a 
marginalized racial minority group (Boykin \& Toms, 1985). African American parents often face this triple quandary in parenting, such that they must try to balance responsibilities of encouraging cultural pride, preparing children for life in mainstream society, and helping children to deal with racism and discrimination (Boykin, 1986). African American parents can serve as a buffer to their children to lessen the negative effects of being a part of a marginalized racial group status by helping them to thrive in an environment that has been historically discriminatory (McAdoo, 1998). Racial socialization can be defined as exposure to cultural practices and objects, encouragement of cultural pride and knowledge about African Americans, discussions about discrimination and coping strategies, and instruction on how to succeed in society (Coard \& Sellers, 2005; Hughes et al., 2006). These socialization strategies can be verbal behaviors (e.g., direct statements regarding race), modeling of behaviors (e.g., child indirectly learns how to act as an African American via observation), and exposure to various environments (Thornton, Chatters, Taylor, \& Allen, 1990). There are common racial socialization strategies that African Americans engage in, these include racial pride, socialization behaviors, racial barriers, egalitarianism, self-worth, and negative messages.

Racial pride and socialization behaviors. Racial pride refers to the parental practices that emphasizes Black unity and teach children about their heritage and history, promote traditions and racial, cultural and ethnic pride, either deliberately or implicitly (Hughes, Bachman, Ruble \& Fuligni, 2006). Examples include, discussing historical or cultural African American figures, celebrating Kwanzaa, eating and cooking ethnic foods, or going to an African American history museum. These types of socialization behaviors promote cultural traditions and establish cultural, racial, and ethnic pride (Hughes et al., 2006). African American parents are more likely to endorse these types of behaviors and engage in these cultural socialization 
behaviors more frequently than any other racial socialization behaviors (Hughes, 2003; Hughes et al., 2006). Racial pride and engaging in racial socialization behaviors are associated with more positive child outcomes such as higher well-being and lower depressive symptoms (Neblett et al., 2008), lower internalizing and externalizing behaviors (Caughy, O’Campo, Randolph \& Nickerson, 2002), higher self-esteem (Constantine \& Blackmon, 2002), greater academic motivation, academic achievement, and self-concept (Bowman \& Howard, 1985; Hughes et al., 2006) and lower levels of perceived racial discrimination and failing grades (Wang \& Huguley, 2012).

Racial barriers. Another racial socialization strategy focuses on racial barriers (also known as preparation for bias), which is when a parent promotes their children's awareness of discrimination and racism in society and teaches them how to cope with such stressors (Hughes et al., 2006). For example, parents may teach their children about the racial inequalities occurring in the present society involving wealth, poverty rates, educational opportunities, unemployment rates, and incarceration rates. Research has found that parents who utilized racial barriers messages had adolescents with a more well-developed racial self-identity (Stevenson, 1995) and higher self-esteem (Harris-Britt et al., 2007). Additionally, Neblett Jr. and colleagues (2006) found that racial barrier messages were positively related to academic motivation. However, other studies found opposing results, such that racial barrier messages were correlated with greater negative academic engagement (Hughes, Witherspoon, Rivas-Drake, \& West-Bey, 2009). It is speculated that the frequency of these messages determines the child outcome. For example, Harris-Britt and colleagues (2007) found that lower frequency of racial barrier messages exacerbated the negative effect discrimination had on adolescents' self-esteem. However, when parents gave moderate levels of racial barrier messages, there was no relationship between racial 
discrimination and lower self-esteem, concluding that moderate racial barriers may be more optimal. Fischer and Shaw (1999) found that receiving more racial barrier messages reduced the negative relationship between racist events and poorer mental health for African American young adults than those who reported fewer racial barrier messages. Other researchers have found no significant relationship between racial barrier messages and adolescent outcomes (Neblett et al., 2009) or child outcomes (Caughy, O’Campo, Randolph \& Nickerson, 2002).

Egalitarianism and self-worth. Parents also can encourage their children to value individual qualities over racial group membership and emphasize interracial equality, which is known as egalitarianism (Hughes et al., 2006; Spencer, 1983). An example includes teaching one's child to not judge a person based on their race, but rather, based on their personality and morals. Another racial socialization type that does not focus on race is self-worth, which is when parents encourage their child to prioritize their individual worth outside of their race. Egalitarian messages are related to fewer problem behaviors and higher psychological well-being among adolescents (Neblett, White, Ford, Philip, Nguyên, \& Sellers, 2008). Additionally, Neblett and colleagues (2008) found that self-worth was related to high well-being and low levels of stress and problem behaviors. Similarly, Neblett Jr. and colleagues (2006) found that non-race related socialization messages, such as self-worth and egalitarian messages, were related to greater academic curiosity and persistence along with higher grade-point-averages in middle and high school students.

Negative messages. A parent could also reinforce negative stereotypes or express other negative thoughts about being an African American to their child, which is known as negative messages (Hughes et al., 2006). This form of racial socialization is understudied. However, the few studies that examine this construct (e.g., Neblett et al., 2008; Neblett Jr. et al., 2006) found 
that parents who express negative messages have adolescents with greater depressive symptoms, problem behaviors, and lower psychological well-being. Additionally, adolescents who reported receiving negative messages about African Americans from their parents showed less academic persistence (Neblett Jr. et al., 2006). Although the average amount of negative messages reported by adolescent were relatively low and the least frequent than all the other racial socialization types (e.g., racial pride, racial barrier, etc.), negative messages were related to high levels of depressive symptoms, stress, problem behaviors, and lower levels of well-being (Neblett et al., 2008).

\section{Discrimination and Racial Socialization}

One factor likely to affect ways in which parents racially socialize their children may be the parents' own experiences with racial discrimination. Previous research has found that African American parents who experience racial discrimination are likely to anticipate that their child will also experience it, and thus may feel obligated to provide their children with strategies to cope (Hughes, 2003; Hughes \& Chen, 1997). Parents who experience racial discrimination are more likely to engage in racial socialization behaviors (Benner \& Kim, 2009; Hughes, 2003; White-Johnson et al. 2010). For example, parents' discrimination experiences predicted socializing their child with higher levels of racial barriers (Hughes, 2003) and racial pride (Hughes \& Johnson, 2001).

Not only do parents' own experiences with racial discrimination influence their racial socialization, but their beliefs that their child is experiencing racism also drives their racial socialization behaviors. For example, when parents believed that their child had experienced discrimination by adults and/or peers, these parents were more likely to report using more preparation for bias and promotion of mistrust (Hughes \& Johnson, 2001). The present study 
sought to corroborate previous studies on investigating the relationship between racial discrimination and racial socialization. However, this study is novel in its investigation of emotion socialization and testing if emotional beliefs mediate the association between racial discrimination and emotion socialization.

\section{Emotion Socialization}

Children often learn about their emotions and how to regulate them through their parents or caregivers (Eisenberg et al., 1998). There are many different strategies parents use to socialize their child's emotion. Parental emotion socialization is the process in which the parent intentionally or unintentionally influences their child's emotional development, often by the parents' modeling emotion regulation, discussing emotion and reactions with their child and responding to their child's expression of emotions (Eisenberg et al., 1998). Children learn how to regulate both positive and negative affect. Positive affect socialization can be defined as how a parent socializes their child's positive emotions (e.g., joy, happiness, excitement) whereas negative affect socialization is how a parent socializes their child's negative emotions (e.g., sadness, anger, afraid).

Positive affect socialization. There is limited research that examines parental positive affect socialization. However, research has shown that parents can model and reinforce different positive emotion regulation strategies such as savoring and dampening (e.g., Gentzler, Ramsey, \& Black, 2015; Moran, Root, Vizy, Wilson, \& Gentzler, 2019). Savoring can be defined as utilizing various thoughts or behaviors to upregulate or maintain positive emotions and is related positive outcomes such as increased happiness and self-esteem (Bryant, 2003). Examples of savoring include anticipating positive events/emotions, appreciating and cherishing the moment, prolonging the positive experience, sharing the positive event/emotion with others, and 
reminiscing or reflecting on the positive event (Bryant, 2003; Gentzler, Palmer, \& Ramsey, 2016). Parents who encourage savoring in their children have children who report more savoring positive emotions themselves (e.g., Moran et al., 2019). Conversely, dampening can be defined as thinking negative thoughts about a positive experience or emotion and is related to lower levels of positive affect and higher levels of depressive symptoms or internalizing and externalizing problems (Bijttebier, Raes, Vasey, \& Feldman, 2012; Feldman, Joormann, \& Johnson, 2008; Gentzler et al., 2013). Parents who responded negatively (e.g., dampen) to their child's positive affect had children with higher levels of depressive symptoms (Yap et al., 2008) and externalizing and internalizing behaviors (Yi, Gentzler, Ramsey, \& Root, 2016).

Negative affect socialization. Contrary to the research on positive affect socialization, there is an immense amount of research on negative affect socialization. Parents can respond to their child's negative emotions in a variety of ways that are often categorized as either effective/supportive or ineffective/unsupportive A more effective strategy is accepting and rewarding (i.e., supporting) a child's negative affect. Parents who engage in rewarding socialization behaviors comforts, empathizes, and coaches the child to resolve the problem causing the negative emotion (Magai, 1996). Parents who engage in more supportive negative emotion socialization strategies (e.g., coaching and accepting) have children with fewer behavior problems (Hooven, Gottman, \& Katz, 1995; Katz \& Hunter, 2007). Unsupportive negative emotion socialization can include punishing (e.g., discouraging a child from expressing negative emotion), neglecting (e.g., ignoring negative emotions), overriding (e.g., distracting negative emotions) and magnifying (e.g., responding by expressing the same or stronger negative emotions; Magai 1996). Parents who engage in unsupportive emotion socialization strategies teach their child that these emotions are inappropriate. Unsupportive negative emotion 
socialization (e.g., punish or dismiss negative emotions is associated with poor outcomes for the child such as poor emotion regulation (Lagace-Seguin \& Coplan, 2005), poor social competencies (Fabes, Leonard, Kupanoff, \& Martin, 200), and psychological distress (Garside \& Klimes-Dougan, 2002).

\section{Emotion Socialization in African Americans}

Positive emotion socialization. African Americans tend to respond in supportive ways when handling their child's positive emotions. McKee and her colleagues (2015) examined positive affect socialization of African Americans and found that the mothers typically responded in ways likely to increase their child's positive affect by reinforcing the child's positive affect, focusing on the event that elicited their child's positive affect, and showing interest by asking their child questions. Some mothers also reported taking part in the activity that elicited the child's positive affect and the mothers often expressed their own positive affect to their child (McKee et al., 2015). There has also been comparative research that found that African Americans are more likely to up-regulate their child's positive emotions than nonAfrican Americans. For example, African American mothers are more likely to engage in positive emotion talk with their children than are European American mothers (Garrett-Peters et al., 2008). Additionally, Parker and his colleagues (2012) found that African Americans were more likely than European Americans and Lumbee American Indians to value authentic expression of their child's positive emotions, even when the emotion was intense, suggesting that African Americans may help their child upregulate any type of positive emotion (e.g., happiness vs. excitement). These racial differences in emotion socialization behaviors between African American parents and non-African American parents may be due to African American experiences with racism and discrimination because parents may be socializing their children 
based on their racial discrimination experiences. The present study examined whether experiences with racial discrimination are related to African Americans' emotion socialization behaviors. Examining this relationship will advance researchers' understanding of motives underlying African American parents' emotion socialization, which could help in interventions for African American parenting.

Negative emotion socialization. Compared to European Americans, African American parents are more likely to respond to their child's negative emotions in more dismissive ways (Halberstadt, Craig, Lozada, \& Brown, 2011; Nelson, Leerkes, O’Brien, Calkins, \& Marcovitch, 2012; Parker et al., 2012). African Americans are often stereotyped as being aggressive and angry. For example, African American males were perceived as angrier and more hostile than White males (Kang \& Chasteen, 2009). It is speculated that African American parents' discouragement of their child's negative emotions may be attributed to their beliefs about the negative consequences of such behavior (e.g., stereotyped as the "angry black woman") and may prepare their child for the negative views of society (e.g., Nelson et al., 2012). Although these dismissive behaviors have been shown to be ineffective and detrimental to European Americans, these dismissive practices have a different effect on African Americans, such that dismissive negative emotion socialization behaviors were related to higher depressive symptoms for European Americans children but not for African Americans (Leerkes, Supple, Su, \& Cavanaugh, 2013; Nelson et al., 2013; Smith \& Walden, 2001). Additionally, Nelson and colleagues (2013) found that African American parents who encouraged their children to express negative emotions had children with poorer academic performance and less skillful peer interactions than parents who dismissed their children's negative emotions. Thus, emotion 
socialization strategies that encourage the suppression of negative emotion may not be maladaptive - but rather culturally adaptive - for African Americans (Cole \& Tan, 2007).

Generally, all negative emotions tend to be suppressed in African American families, not just anger. African Americans report that expressing any negative emotions, such as disgust and sadness, is unacceptable (Matsumoto, 1993). African Americans' history of oppression has led African Americans to value emotional self-control and limit self-disclosure (Consedine \& Magai, 2002). It is speculated that self-control (e.g., child obedience and compliance) in African Americans is important to interact successfully with the majority culture since African American children face more discrimination from the majority culture when exhibiting negative emotions (Kang \& Chasteen, 2009; Stevenson et al., 2002). Therefore, African American parents dismiss all negative emotions regardless if the negative emotion is submissive (e.g., sadness or fear) or dominant (e.g., anger; Nelson, Leerkes, O'Brien, Calkins, \& Marcovitch, 2012).

\section{Predictors of Racial and Emotion Socialization}

Research has found that parenting practices are influenced by parents' life experiences and stressors (Belsky, 1984; Murry, Brody, Simons, Cutrona, \& Gibbons, 2008). For example, the family stress model suggests that family stressors can increase parents' mental health problems, which then hinders parents' ability to provide nurturing and involved parenting, thus leading to negative child outcomes (Conger \& Donnellan, 2007). Discrimination is an everyday stressor in African American's lives that can influence African American parenting. For example, Brody and colleagues (2008) found that perceived discrimination increased the mothers' stress-related health problems (e.g., depressive symptoms), thereby decreasing the mothers' competence-promoting parenting (e.g., involved-vigilant parenting, warmth, and closeness). Similarly, Anderson and colleagues (2015) found that greater parental perceived 
discrimination was associated with higher levels of depressive symptoms, which were in turn associated with less effective parenting practices, such as more laxness (e.g., setting no limits) or being emotionally overreactive. Although previous research examined the role discrimination has on parenting, few examined discrimination and its relationship to parental socialization behaviors.

Racism and discrimination. Dunbar and colleagues (2017) created an integrative conceptual model of adaptive racial/ethnic and emotion socialization. This newly established model has yet to be studied empirically. However, it is one of the first models to consider the role the child's experiences with racism and discrimination has on parental emotion and racial socialization (presented in Figure 1). The model suggests that broader influential factors (e.g., child, family, and neighborhood) along with the child's experience with discrimination influence parental racial and emotion socialization. These parenting behaviors (e.g., emotion and racial socialization) have an effect on the child's emotion regulation and adaption (e.g., social and emotional development). Although it is important to examine children's experiences with discrimination in relation to parenting practices, it is also imperative that researchers examine parents' experiences with discrimination in relation to their socialization behaviors due to the possible negative child outcomes.

Parents' beliefs about emotions. Prior research has failed to examine racial discrimination as the predictor of emotion socialization behaviors. However, research has examined how parents' beliefs about their own emotions influence their emotion socialization behaviors. The term, meta-emotion philosophy, is used to describe parents' own beliefs about emotions and how they will teach, express, label, and regulate emotions to their children (Gottman, Katz, \& Hooven, 1996). Parents' beliefs about emotions is a key aspect of emotion 
socialization because these beliefs motivate the parents' reactions to their child's emotions (Dix, 1992). Eisenberg, Spinrad, and Cumberland (1998; presented in Figure 2) established a heuristic model of the socialization of emotions. In this well-established model, parenting characteristics such parents' sex, personality, and their emotion related beliefs and values are a predictor of emotion related parenting practices (e.g., emotion socialization). This model excludes predictors of parenting characteristics. In the current study, it was proposed that past historical experiences such as racism and discrimination influence parenting characteristics such as parental emotional beliefs and in turn, these emotional beliefs would be related to parents' emotion socialization behaviors.

Parents' beliefs about child's emotions. Additionally, parents' beliefs about their child's emotions can also predict the parents' emotion socialization behaviors. There are many different parental emotional beliefs regarding their child's emotions that can influence the parents' emotion socialization behaviors. Parents can have accepting or nonaccepting beliefs about emotions, varying levels of awareness of their own or child's emotions, (Gottman, Katz, \& Hooven, 1996). This study examines parents' beliefs in valuing positive and negative emotions and beliefs that the expression of children's positive or negative emotions can be costly/dangerous. Parents who value their child's emotions (e.g., positive and negative) consider emotions to be beneficial and worthy of attention (Halberstadt, Thompson, Parker \& Dunsmore, 2008). Contrary, parents who devalue their child's emotions believe that children's emotions are problematic or costly and should be avoided if experienced too frequently or intensely (Parker et al., 2012). No research has explicitly examined how African American parents' experience of racial discrimination predicts parents' beliefs about emotions and resulting socialization behaviors. 


\section{The Present Study}

The present study was the first to examine whether African American parents' past experiences with racism and discrimination influences both racial and emotional parental socialization practices. Specifically, this study examined whether racial discrimination experiences predicted positive and/or negative emotion socialization behaviors. The majority of research examine general emotion socialization behaviors (e.g., positive and negative). This study examined specific positive (e.g., happiness and pride, and negative emotions (e.g., anger, sadness, fear) to investigate whether discrimination affects specific emotions differently. This study could possibly corroborate previous research on racial discrimination experiences predicting racial socialization behaviors. Additionally, this study examined whether parental beliefs of their child's positive and negative emotions mediates the relationship between racial discrimination and socialization behaviors. Because parental emotion socialization behaviors have been shown to relate to children's emotion regulation (Lagace-Seguin \& Coplan, 2005) and various behavioral problems (Eisenberg et al., 1999; Stoolmiller, Wilson, \& Yamamoto, 2003), it is important to examine whether racial discrimination influence parenting behaviors for intervention purposes. The study also adds to the literature by investigating differences within an African American sample of parents. Given that much of the research on parenting and socialization has either included samples of limited diversity (e.g., mostly White parents; Graham, 1992) or has compared parenting across racial groups (e.g., Black vs. White parents; Garrett-Peters et al., 2008; Halberstadt, Craig, Lozada, \& Brown, 2011; Parker et al., 2012), this study was expected to provide novel information on how and why there may be variation within African American parents.

\section{Research Questions and Hypothesis}


Research Question 1: Are experiences with racial discrimination associated with parents' racial socialization behaviors?

Hypothesis 1a: Parents who report experiencing higher levels of racial discrimination were expected to report higher levels of racial pride, racial barriers, self-worth messages and socialization behaviors on the Racial Socialization Questionnaire - Parent Version (WhiteJohnson \& Sellers, 2010).

Hypothesis 1b: Parents who report experiencing higher levels of racial discrimination were expected to report lower levels of egalitarian and negative messages on the Racial Socialization Questionnaire - Parent Version (White-Johnson \& Sellers, 2010).

Research Question 2: Are experiences with racial discrimination associated with parents' positive emotion socialization behaviors?

Hypothesis 2a: Parents who report experiencing higher levels of racial discrimination were expected to report higher levels of supportive responses (i.e., rewarding and magnifying) to their child's positive affect (i.e., happiness and pride) on the Emotions as a Child scale (Magai, 1996).

Hypothesis 2b: Parents who report experiencing higher levels of racial discrimination were expected to report lower levels of unsupportive responses (i.e., punish, neglect, override) to their child's positive affect (i.e., happiness and pride) on the Emotions as a Child scale (Magai, 1996).

Research Question 3: Are experiences with racial discrimination associated with parents' positive emotional beliefs? 
Hypothesis 3a: Parents who report experiencing higher levels of racial discrimination were expected to report higher levels of valuing their child's positive emotions (i.e., happiness and pride) using the Parents' Beliefs About Children's Emotions (Halberstadt et al., 2013).

Hypothesis 3b: Parents who report experiencing higher levels of racial discrimination were expected to report lower levels of the belief that positive emotions (i.e., happiness and pride) are costly/dangerous using the Parents' Beliefs About Children's Emotions (Halberstadt et al., 2013).

Research Question 4: Do parents' positive emotional beliefs mediate the association between racial discrimination and positive emotion socialization?).

Hypothesis 4a: Parents who report experiencing higher levels of racial discrimination were expected to report higher of valuing their child's positive emotions (i.e., happiness and pride), which were expected to predict higher levels of supportive responses (i.e., rewarding and magnifying) to their child's positive affect.

Hypothesis 4b: Parents who report experiencing higher levels of racial discrimination were expected to report lower levels of the belief positive emotions (i.e., happiness and pride) are costly/dangerous, which were expected to predict higher levels of supportive responses (i.e., rewarding and magnifying) to their child's positive affect.

Research Question 5: Are experiences with racial discrimination associated with parents ' negative emotion socialization behaviors?

Hypothesis 5a: Parents who report experiencing higher levels of racial discrimination were expected to report lower levels of supportive responses (i.e., reward, override) to their child's negative affect (i.e., sadness, anger, and fear) on the Emotions as a Child Scale (Magai, 1996). 
Hypothesis 5b: Parents who report experiencing higher levels of racial discrimination were expected to report higher levels of unsupportive responses (i.e., punishing, neglecting, magnify) to their child's negative affect (i.e., sadness, anger, and fear) on the Emotions as a Child Scale (Magai, 1996).

Research Question 6: Are experiences with racial discrimination associated with parents' negative emotional beliefs?

Hypothesis 6a: Parents who report experiencing higher levels of racial discrimination were expected to report lower levels of valuing their child's negative emotions (i.e., anger, sadness, fear) using the Parents' Beliefs About Children's Emotions (Halberstadt et al., 2013).

Hypothesis 6b: Parents who report experiencing higher levels of racial discrimination were expected to report higher levels of the belief that negative emotions (i.e., anger, sadness, fear) are costly using the Parents’ Beliefs About Children's Emotions (Halberstadt et al., 2013). Research Question 7: Do parents' negative emotional beliefs mediate the association between racial discrimination and negative emotion socialization?

Hypothesis 7a: Parents who report experiencing higher levels of racial discrimination were expected to report lower levels of valuing negative emotion, which were expected to predict higher levels of unsupportive responses (i.e., punishing, neglecting, overriding) to their child's negative affect (i.e., sadness, anger, fear).

Hypothesis 7b: Parents who report experiencing higher levels of racial discrimination were expected to report higher beliefs that negative emotions are costly/dangerous, which were expected to predict higher levels of unsupportive responses (i.e., punishing, neglecting, overriding) to their child's negative affect (i.e., sadness, anger, fear).

\section{Method}




\section{Participants}

The participants in the overall study $(N=942)$ included parents of all different racial and ethnic backgrounds with at least one child between the ages of 8 and 18 years old. Participants were predominantly recruited through Amazon Mechanical Turk (MTurk). All registered MTurk users with at least one child between the ages of 8 and 18 years old from the United States (i.e., U.S. IP addresses) were eligible to participate in the study. Additionally, participants were recruited from Facebook. If the parent reported having more than one child, the participants were asked to choose one child that they will use as reference when answering the survey questions. Parents were not given any criteria about which child to choose.

For the purpose of this study, only African American parents were examined. The sample included 406 parents with ages ranging from 22 to 57 years old (53\% male, $M_{a g e}=35$ years old, $S D=6.76)$. The participants were from over 40 states across the U.S, from counties ranging in the percentage of African Americans $(0-92 \%, M=19 \%)$. The majority of the participants were married (80\%), obtained a 4-year college degree or higher (82\%), and worked full time (40 or more hours a week; 84\%). When asked their level of difficulty paying their bills, $17.1 \%$ reported “a great deal", 36.6\% reported "some", 31.9\% reported "a little", and 14.3\% reported "none at all”. See Table 1 for additional demographic information.

The final sample of African Americans were derived from a larger sample of 519 African American parents. The participants were asked "What one race do you most strongly identify with?" and out of the 942 parents that completed the survey, 519 parents reported strongly identifying as an African American. However, over 100 participants were deleted from the sample due to failing validity check questions, missing data, multivariate outliers, etc. (see Figure 3). 


\section{Procedure}

Participants were recruited through Amazon Mechanical Turk (MTurk). MTurk is an internet marketplace that allows businesses and researchers, to recruit anonymous participants to complete surveys or tasks for a small payment. Research on MTurk shows that MTurk participants are more diverse (race, demographic, gender age, education, etc.) than typical research samples (e.g., American college students; Berinsky, Huber, \& Lenz, 2012; Buhrmester, Kwang, \& Gosling, 2011). Although completed independently online, the data obtained from MTurk respondents have been found to be as reliable as those obtained by traditional methods, due to internal motivation and compensation rates (Buhrmester et al., 2011; Mason \& Watts, 2009). The participants in the current study who met the criteria (i.e., U.S. parent) were invited to participate in the study. Additionally, a few participants were recruited on Facebook by posting a Facebook ad encouraging parents to complete the survey. However, these participants were deleted due to extensive missing data.

The beginning of the survey included a description of the study and consent to participate. The survey took the participants no more than an hour to complete and included various validity items throughout the survey to guarantee legitimacy (e.g., "select "extremely agree for this response"). Also, to ensure the parent had a child between the ages of 8 and 18 years old, at different points in the survey, the parents reported their child's age, birthdate, and initials. If the parent had multiple children, they were prompted to only choose one child that they would answer the survey questions for. The participants that completed the survey via Mturk were compensated \$1 through the MTurk payment system and the participants that completed the survey on Facebook were put into a drawing to win one of five $\$ 50$ amazon gift cards. 


\section{Measures}

Demographics. Participants reported on a host of demographic questions such as age, sex, income, race. ethnicity, martial statues, and education. Additionally, the survey also assessed the level of difficulty paying bills ("How much difficulty do you have paying your bills?") where higher scores indicate greater level of difficulty paying bills. The parents also reported on the number of children they have, their target child's age, race, ethnicity and sex. The survey included a general race/ethnicity question ("What is your race and ethnicity?") and a specific race question ("What one race do you most strongly identify with"). Only the participants who reported strongly identifying with being an "African American/Black" were analyzed for this study.

Perceived discrimination. The participants reported on their frequency of discrimination experiences using The Schedule of Racist Events (SRE; Landrine \& Klonoff, 1996). For 17 of the 18 items, the participants rated the frequency of racist events in the past year and in their lifetime using a 6 -point scale $(1=$ never happened to $6=$ this has happened almost all of the time). Example items include, "How many times have you been treated unfairly by strangers because you are Black?" and "How many times have people misunderstood your intentions and motives because you are Black?". Additionally, for 17 of the 18 items, participants rated the degree of stressfulness of the events (i.e., "How stressful was this for you") using a 6-point scale $(1=$ Not at All to $6=$ Extremely $)$. The last item (\#18) ask the participants, "How different would your life be now if you HAD NOT BEEN treated in a racist and unfair way" using a 6-point scale $(1=$ Same as now to $6=$ Totally different $)$. A mean score was constructed from each of the subscales including the last item (i.e., frequency of events in the 
past year, frequency of event in entire lifetime, degree of stressfulness and life difference) where higher scores indicate higher levels of the corresponding subscale (see Table 2 for reliability).

The scale previously demonstrated high internal consistency reliability coefficients in previous studies (e.g., .95 for recent racist events, .95 for lifetime racist event, and .94 for degree of stressfulness; Landrine \& Klonoff, 1996). In addition, prior research has shown that when assessing community racism, the inter-rater agreement among neighborhood residents was .84 (Russell et al., 2018). The SRE subscales has demonstrated predictive validity $(r=.31-.38$; $p$ s < .001) through relations with psychiatric symptoms (Derogatis et al., 1974; Landrine \& Klonoff, 1996).

Beliefs about child's emotions. Participants reported on various beliefs that they may hold about children's negative and positive emotions using the original Parents' Beliefs About Children's Emotions questionnaire (PBACE; Halberstadt et al., 2001) and the newly adapted PBACE (Halberstadt et al., 2013). To measure the beliefs that emotions are dangerous/costly, one 4-item subscale from the newly adapted PBACE was used to measure positive emotional beliefs: cost/dangers of positivity (e.g., "Children may not focus on their commitments if they feel too much happiness"; $\alpha=.71$; Halberstadt et al., 2013), and one 4-item subscale from the original PBACE (Halberstadt et al., 2001) was used to measure negative emotion beliefs: negative emotions are dangerous (e.g., "When children get angry, it can only lead to problems"; $\alpha=.89$; Halberstadt et al., 2001).

To measure the beliefs negative emotions should be valued, the newly adapted PBACE (Halberstadt et al., 2013) 4-item subscale, value of anger (e.g., "It is useful for children to feel angry sometimes"; $\alpha=.75$; Halberstadt et al., 2013), was utilized. To measure the belief that positive emotions should be valued, the same value of anger subscale was used, but adapted to 
relate to positive emotions (e.g., "it is useful for children to feel happy sometimes). Halberstadt and colleagues (2013) discussed the importance of distinguishing between various emotions (e.g., positive and negative) in future work investigating parents' beliefs and behaviors. Thus, the scale was modified to include other positive and negative emotions besides happiness and anger. For example, the value of anger items also included a value of sadness and afraid subscale by replacing the term "anger" with the terms "sad" or "afraid" (e.g., original item: "It is useful for children to feel angry sometimes", new item: "It is useful for children to feel sad sometimes"). Additionally, the cost of positivity subscale also included pride in addition to happiness.

For all of the subscales, the participants rated the degree that they agree or disagree with the items using a 6-point Likert scale from $1=$ strongly disagree to $6=$ strongly agree. The mean score was used for each subscale, such that higher scores indicate greater level of agreement with each of the subscales. See Table 2 for the Cronbach alphas for each subscale. All of the subscales have been tested with mothers and fathers from various cultural groups (Halberstadt et al., 2013) with children of various ages (e.g., childhood to late adolescence; Lozada et al., 2016; Morey \& Gentzler, 2017; Rogers et al., 2016). There has been evidence of construct validity by associations with parents' discussions of emotional events and emotional expression (Dunsmore et al., 2009; Halberstadt, Thompson et al., 2008; Perez-Rivera \& Dunsmore, 2011).

Parental socialization of negative and positive emotions. Participants reported on their emotion socialization behaviors using Emotions as a Child scale (EAC; Magai 1996) that was adapted for parent report (Klimes-Dougan et al., 2007). Parents were asked to recall how they respond to their child's negative and positive emotions (e.g., "When your child was sad [or angry, or afraid, happy, proud] what did you do?') by rating items that corresponded with one of five emotion socialization strategies using a 5-point scale from $1=$ not at all typical to $5=$ very 
typical. The five emotion socialization strategies included: reward (e.g., "Buy something my child likes"); punish (e.g., "I express disapproval verbally”); override (e.g., "Tell my child to cheer up"); neglect (e.g., "I don't respond"); and magnify (e.g., "Get tearful or cry"). A mean score was created for each 3-item emotion socialization scale such that higher scores indicate greater likelihood engaging in the particular socialization behavior. The subscales exhibited good reliability (see Table 2).

This measure has been tested on children and parents with children of various ages (e.g., 8 to 18 years old; Briscoe, Stack, Dickson, \& Serbin, 2019; O'Neal \& Magai, 2005; Sanders, Zeman, Poon, \& Miller, 2015; Tillery et al. 2014). The internal reliability of the five subscale scores ranged from .66 to .94 (Magai \& O’Neal, 1997) and the test-retest reliability for the fivesubscale ranged from .49 to .86 among adolescents and young adults across a week time-span (Klimes-Dougan et al., 2001). Convergent validity was indicated by significant correlations between parent and youth reports ( $r=.40$, Kehoe et al., 2014).

Parental racial socialization. Participants reported on their racial socialization behaviors using the Racial Socialization Questionnaire- Parent Version (RSQ-P; White-Johnson \& Sellers, 2010). The RSQ-P was adapted from the Racial Socialization Questionnaire-Teen Version (RSQ-T; Lesane-Brown, Scottham, Nguyen, \& Sellers, 2006). The scale consists of 26 items with 6 subscales: 1) racial pride (e.g., "told the target child that s/he should be proud to be Black"); 2) racial barriers (e.g., "told the target child that some people try to keep Black people from being successful"); 3) egalitarian (e.g., "told the target child the Blacks and Whites should try to understand each other so they can get along"); 4) self-worth (e.g., "told the target child that s/he is somebody special, no matter what anyone says"); 5) negative messages (e.g., "told the target child that learning about Black history is not that important”); and 6) socialization 
behaviors (e.g., "bought the target child books about Black people"). Participants rated how often they engage in each scenario in the past year using a 3-point scale from $0=$ never to $2=$ more than twice. A mean score was created for each subscale (see Table 2 for the subscales' Cronbach alphas) such that higher scores indicate greater frequency of the particular racial socialization behavior.

The measure has been tested on children and parents of children in $3^{\text {rd }}$ grade to college (e.g., Neblett, Banks, Cooper, \& Smalls-Glover, 2013; White-Johnson, Ford, \& Sellers, 2010). The measure has been found to have adequate inter-item reliability with the 6 subscales: racial pride, $\alpha=.63-.64$; racial barriers, $\alpha=.63-.69$; egalitarian, $\alpha=.64-.70$; self-worth, $\alpha=.74-.77$; negative messages, $\alpha=.66-.75$; and socialization behaviors, $\alpha=.73$ (Neblett, Chavous, Nguyên, \& Sellers, 2009; Neblett, Smalls, Ford, Nguyen, \& Sellers, 2009). Additionally, this measure has been predictive of racial identity attitudes and intergroup relation indicating predictive validity (Lesane, Brown, Scottham, Nguyen, \& Sellers, 2006).

\section{Control Variables}

Well-being. Participant reported on their well-being using the Satisfaction with Life Scale (SWLS; Diener, Emmons, Larsen, \& Griffin, 1985) which consists of 5-item $(\alpha=.82)$. Participants respond to questions on a 7-point Likert scale ranging from $1=$ strongly disagree to 7 strongly agree. A mean score was created and higher scores indicate increased life satisfaction/well-being.

Anger expression. Participant reported on their anger expression using the Anger Expression Scale (Spielberger et al., 1985) however only the Anger-out subscale (8 items; $\alpha=$ .88) was utilized. The subscale consists of 8 items (e.g., "I express my anger", "I lose my 
temper", "I argue with others") rated from $1=$ almost never to $4=$ almost always. A mean score was calculated and higher scores indicate greater levels of anger expression.

Depressive symptoms. Participants reported on their depressive symptoms using the 20item $(\alpha=$.93) Center for Epidemiologic Studies Depression Scale (CES-D; Radloff, 1977). Participants were given a list of ways they could have felt or behaved (e.g., "I was happy”, "I felt lonely", "I enjoyed life") and are asked to report how often they felt this way during the past week on a scale from $0=$ Rarely or none of the time (less than 1 day ) to $3=$ Most or all of the time (5-7 days). The sum of the scores were calculated and higher scores indicate the presence of more depressive symptoms.

\section{Results}

\section{Preliminary Analyses}

Prior to analysis, the variables in the study were examined for validity of the participants' responses, missing data, collinearity and the assumptions of multivariate. Using Little's MCAR test, no statistically significant deviation from randomness were found, $p=.10$. Means, standard deviations, and Cronbach's alpha for the main variables can be found in Table 2. Transformation of the data was unnecessary due to no notable deviations from normality. However, 12 participants were excluded from the analyses after being identified through Mahalanobis distance as a multivariate outlier $(48.27, d f=22, p<.001 ; N=406)$.

Bivariate correlations were conducted among all the variables of interest (see Tables 3-5). Specifically, bivariate correlations were conducted on participants' demographic information, such as age, sex, income and the study's main variables (see Table 3). Parents' age, sex, education, difficulty paying their bills were significantly correlated to the main variables, thus these variables were included in all of the models as covariates. Additionally, given the 
associations with parents' sex, a multigroup model was also conducted to test the differences between mothers and fathers (see Appendix H).

Furthermore, because perceived discrimination has been correlated to low levels of wellbeing (Deitch et al., 2003), greater anger expression (Brondolo et al., 2009; Utsey et al., 2000), and higher depressive symptoms (Hudson, Neighbors, Geronimus, \& Jackson, 2016; Sellers et al., 2006; Wong et al 2003), bivariate correlations were conducted among these variables and the study's main variables (see Table 4). However, due to their extremely high correlations (e.g., $r=$ .70-.82) with the variables of interest (e.g., socialization and discrimination), these variables were run in a separate model to avoid issues with covariances. Fortunately, in this separate model, the results remained consistent with the models controlling for participants' demographics (e.g., parents' age, sex, education, difficulty paying bills).

\section{Primary Analyses}

Analysis plan. To address all of the research questions, structural equation models (SEM) were utilized, which allows researchers to test overall models rather than individually predicting multiple outcomes. Additionally, SEM estimates the relationship among variables while adjusting for measurement error and evaluates how well models fit the data (Kline, 2010). Parents' experience of discrimination was included in the model as the independent variable. Racial socialization, positive emotion socialization, and negative emotion socialization were included as dependent variables. Positive and negative emotional beliefs were used as mediators (see Figure 4) using a phantom model approach (Rindskopf, 1984) due to the complexity of the original full model and to focus on the specific hypothesized paths without the influence of other paths. 
To test the models, first the measurement model fit was tested and the fit indexes were examined (e.g., CFI (comparative fit index) > .90; RMSEA (root mean squared error of approximation) <.08; CMIN/DF (chi square/degrees of freedom) $<5$ ) to ensure an appropriate latent structure model was present. If the model showed poor fit, it was re-specified based on modification indices. Additionally, changes were made to allow correlation across error terms. After successful measurement model fit, the full structural model was tested (e.g., estimate Maximum Likelihood, examine fit indexes). The model was re-specified based on modification indices when necessary. After achieving acceptable structural model fit, the direct and indirect effects were examined based on each of the research questions.

Measurement model. First, a measurement model was tested to assess the latent structure of the model. Based on the fit indexes $\left(x^{2} / d f=16.75, p=.000, \mathrm{CFI}=.719, \mathrm{RMSEA}=\right.$ .197), the overall model showed poor fit. Thus, many modifications were performed. Originally, two latent variables were created for racial socialization behaviors: dominant racial socialization and non-dominant racial socialization. Racial pride, racial barriers, self-worth and socialization behaviors were expected to load onto the dominant racial socialization latent variable.

Egalitarian and negative messages were expected to load onto the non-dominant racial socialization latent variable. However, the two racial socialization latent variables (i.e., dominant racial socialization, non-dominant racial socialization) were combined due to poor factor loading among the egalitarian variable (.16). Additionally, the negative messages variable was removed from the dominant racial socialization latent variable because it was the only ineffective racial socialization behavior related to negative child outcomes thus it no longer conceptually fit with the rest of the racial socialization behaviors. 
Furthermore, for the two latent variables created to assess beliefs about negative affect and positive affect, the subscales, value of negative/positive emotions and negative/positive emotions are dangerous, were expected to load onto the latent variables. However due to poor factor loadings (.19 and .17 respectively) the two latent variables (NA Beliefs and PA Beliefs) were deleted and the observed variables (i.e., value NA, value PA, NA dangerous, PA dangerous) remained. After these adjustments, the measurement model proceeded to have poor fit $\left(x^{2} / d f=19.91, p=.000, \mathrm{CFI}=.784, \mathrm{RMSEA}=.216\right)$. Thus, the model was divided into two separate models. One model that tested positive affect beliefs and positive emotions socialization (see Figures 5 and 6) and another that tested negative affect beliefs and negative emotion socialization (see Figures 7 and 8). Racial socialization was included in both of these models (though a follow-up model was conducted with racial socialization in its own model; see Figure 9).

\section{Racial Discrimination and Racial Socialization}

Research Question 1: The first research question addressed whether experiences with racial discrimination were associated with African American parents' racial socialization behaviors. As previously stated, a latent variable was created for racial socialization behaviors which excluded the negative message variable. Racial discrimination did not predict the racial socialization latent variable in both models (i.e., positive emotion and negative emotion models; $\beta=.01, p=.44)$

However, when examining racial socialization behaviors individually significant correlations arose (see Table 5). Thus, hypothesis 1a that African American parents who report higher levels of discrimination would report higher levels of racial pride, racial barriers, selfworth messages, and socialization behaviors, was partially supported with bivariate correlations, 
by finding a positive significant relationship between parents' experience with discrimination racial barriers $(r=.27, p<.001)$ and socialization behaviors $(r=.13, p=.01)$.

Contrary to prediction, higher reports of parents' racial discrimination were correlated with less racial pride $(r=-.10, p=.04)$ and self-worth messages $(r=-.20, p=.000)$. Additionally, hypothesis $1 \mathrm{~b}$ that African American parents experiencing racial discrimination would be related to lower levels of egalitarian and negative messages, was not supported because parents' experiences with racial discrimination was not significantly correlated to egalitarian messages $(r=-.07, p=.17)$. Racial discrimination was correlated with negative messages, however in the opposite direction predicted such that higher reports of racial discrimination was correlated to more negative messages $(r=.61, p=.000)$.

Due to the conflicting findings that parents' discrimination was not related to the latent variable for racial socialization when included in models with emotion socialization (see Table 7 and 8), but parents' discrimination was related to specific racial socialization subscales, separate SEM was conducted predicting the 6 racial socialization subscales (see Figure 9). The bivariate correlations remained significant in that parents' discrimination still predicted various racial socialization strategies (e.g., racial pride, racial barriers, self-worth, and negative messages) when using SEM and controlling for parents' age, sex, education and difficulty paying bills (Figure 9).

\section{Positive Emotions Models}

For the model with positive emotions, to examine the measurement among 3 latent variables (supportive positive emotion socialization, unsupportive positive emotion socialization, and racial socialization) a measurement model was conducted (see Figure 5). The measurement model was run and provided poor fit $\left(x^{2} / d f=5.81, p=.000, \mathrm{CFI}=.95, \mathrm{RMSEA}=.10\right)$. 
Originally, for the supportive positive socialization latent variable, reward, magnify, and override subscales were expected to load on to it and for the unsupportive positive socialization latent variable punish and ignore subscales were expected to load on to the created latent variable. However, overriding positive affect loaded more strongly to the unsupportive positive emotion socialization latent variable than the supportive positive emotion socialization latent variable thus this adjustment was made. Additionally, after covarying error terms the model fit improved $\left(x^{2} / d f=4.62, p=.000, \mathrm{CFI}=.967, \mathrm{RMSEA}=.07\right.$; see Figure 5). A structural model was then conducted to examine the association of all the constructs (e.g., discrimination, emotion beliefs, emotion socialization, and racial socialization) including covariates (e.g., parents' age, sex, difficulty paying bills, and education). After removing non-significant parameters and allowing covariates to covary with each other, the model achieved acceptable model fit $\left(x^{2} / d f=\right.$ $3.23, p=.000, \mathrm{CFI}=.951, \mathrm{RMSEA}=.074$; see Figure 6 ). This model was used to test research questions 2,3 and 4.

Research Question 2: The second research question examined whether racial discrimination experiences are associated with parents' positive emotion socialization behaviors. The direct effects of the structural equation model for positive affect, indicated that hypothesis 2a was not supported (see Table 7). Specifically, it was hypothesized that higher levels of racial discrimination would be associated with higher levels of supportive positive emotion socialization behaviors, but reports of racial discrimination did not predict supportive positive affect socialization behaviors $(\beta=-.007, p=.81)$. Additionally, hypothesis $2 \mathrm{~b}$, that parents experiencing high levels of racial discrimination would report higher levels of unsupportive positive emotion socialization behavior, was not supported. Results indicated a positive significant relationship between parents' experience with discrimination and greater 
unsupportive responses (i.e., rewarding and magnifying) to their child's positive affect $(\beta=.31$, $p=.001)$.

Research Question 3: The third research question examined whether racial discrimination experiences are associated with African American parents' positive emotional beliefs. The direct effects of the structural equation model indicated that hypothesis $3 \mathrm{a}$ that African American parents who reported experiencing higher levels of racial discrimination would report higher levels of valuing their child's positive emotions was not supported. Specifically, there was not a significant positive relationship between African American parents' experiences with racial discrimination and valuing their child's positive emotions $(\beta=-.038, p=$ .34). Hypothesis $3 \mathrm{~b}$ stated that there would be a significant negative relationship between African American parents' experiences with racial discrimination and the belief that positive emotions are costly/dangerous. This hypothesis was not supported. Conversely, higher reports of racial discrimination predicted greater beliefs that positive emotions are costly/dangerous $(\beta=$ $.541, p=.000)$

Research Question 4: The fourth research question addressed whether African American parents' positive emotional beliefs mediated the association between racial discrimination and positive emotion socialization.

Mediation with valuing positive emotions. Reports of racial discrimination did not significantly predict the belief of valuing more positive emotions. Thus, hypothesis $4 \mathrm{a}$, that higher levels of racial discrimination would be associated with valuing positive emotions which in turn predict higher levels of supportive positive emotion socialization behaviors, could not be tested. 
Mediation with positive emotions costly/dangerous. However, parents' experience with racial discrimination did predict the belief the positive emotions are costly/dangerous. Therefore, to test hypothesis $4 \mathrm{~b}$, the belief that positive emotions are costly/dangerous was examined as a mediator between racial discrimination and positive emotion socialization behaviors. Specifically, it was hypothesized that higher levels of racial discrimination would be related to lower levels of the belief that positive emotions are costly/dangerous, which would predict higher levels of supportive positive emotion socialization behavior. Using the phantom variable model, this hypothesis was not supported. The indirect path through parents' beliefs positive emotions are costly/dangerous, was not significant for supportive positive emotion socialization behaviors $(\beta=-.03,90 \% \mathrm{CI}=-.06, .01, p=.22)$. However, there was a significant indirect effect found for emotion beliefs and unsupportive positive emotion socialization. Specifically, parents' experiences with racial discrimination predicted higher beliefs that positive emotions are costly/dangerous, which predicted higher levels of unsupportive responsive (e.g., rewarding and magnifying) to their child's positive affect $(\beta=.29,90 \% \mathrm{CI}=.25, .34, p=.000)$.

\section{Negative Emotion Models}

For the model regarding negative emotions, the measurement among 3 latent variables (supportive negative emotion socialization, unsupportive negative emotion socialization, and racial socialization) were examined (see Table 7). The measurement model was run and provided poor fit $\left(x^{2} / d f=11.19, p=.000, \mathrm{CFI}=.887, \mathrm{RMSEA}=.16\right)$. However, after covarying error terms the model fit improved $\left(x^{2} / d f=3.96, p=.000, \mathrm{CFI}=.982, \mathrm{RMSEA}=.08\right.$; see Table 7$)$. A structural model was then conducted to examine the association of all the constructs (e.g., discrimination, emotion beliefs, emotion socialization, and racial socialization) including covariates (e.g., parents' age, sex, difficulty paying bills, and education). After removing non- 
significant parameters and allowing control variables to covary with each other the model achieved mediocre model fit $\left(x^{2} / d f=4.29, p=.000, \mathrm{CFI}=.927, \mathrm{RMSEA}=.08\right.$; see Table 8$)$. This model was used to test research questions 5,6 , and 7 .

Research Question 5: The fifth research question examined whether racial discrimination experiences were associated with African American parents' negative emotion socialization behaviors. Hypothesis 5a that racial discrimination would predict lower levels of supportive negative emotion socialization behaviors, was tested by examining the direct effects of the structural equation model. Hypothesis 5a was not supported, such that higher racial discrimination experiences predicted more supportive negative affect socialization $(\beta=.17, p=$ .02). However, hypothesis $5 \mathrm{~b}$ that racial discrimination would predict higher level of unsupportive negative emotion socialization behaviors, was supported by finding a positive significant relationship between African American parents' experience with racial discrimination and unsupportive responses (i.e., punish, magnify, neglect) to their child's negative affect (see Table 8). Specifically, reports of more racial discrimination predicted greater unsupportive negative emotion socialization behaviors $(\beta=.60, p=.000)$.

Research Question 6: The sixth research question examined whether racial discrimination experiences were associated with African American parents' negative emotional beliefs. Hypothesis 6a that higher levels of racial discrimination would be related to lower levels of valuing children's negative emotions, was tested by examining the direct effects of the structural equation model (see Table 8). Hypothesis 6a was not supported. The association for valuing children's negative emotions was in the opposite direction as expected. Specifically, higher reports of African American parents' experiences with racial discrimination predicted high levels of valuing their child's negative emotions $(\beta=.40, p=.000)$. However, hypothesis 
$6 \mathrm{~b}$, that racial discrimination would predict higher beliefs that negative emotions are costly/dangerous, was supported by finding a significant positive relationship between African American parents' experiences with racial discrimination and the belief that negative emotions are costly/dangerous $(\beta=.46, p=.000)$.

Research Question 7: The seventh research question addressed whether African American parents' negative emotional beliefs mediate the association between racial discrimination and negative emotion socialization. Higher reports of racial discrimination experiences predicted higher levels of valuing negative affect and higher beliefs that negative emotions are costly/dangerous. Thus, both emotional beliefs (i.e., value negative affect and negative affect costly/dangerous) were examined as mediators between racial discrimination and negative emotion socialization behaviors (i.e., unsupportive and supportive).

Mediation with valuing negative emotions. Using the phantom variable model approach, hypothesis $7 \mathrm{a}$, that higher levels of racial discrimination would be related to lower levels of valuing children's negative emotions, which in turn predict higher levels of unsupportive negative emotion socialization behaviors, was not supported $(\beta=.003,90 \% \mathrm{CI}=.001, .05, p=$ .09). Additionally, there was not a significant indirect effect found between African American parents' experiences with discrimination predicting higher levels of supportive responses through higher levels of valuing children's negative emotions $(\beta=.003,90 \% \mathrm{CI}=.00, .01, p=.10)$.

Mediation with negative emotions as costly/dangerous. Additionally, running the phantom variable model provided evidence to support the hypothesis $7 \mathrm{~b}$ that higher negative emotion beliefs would mediate the association between racial discrimination experiences and unsupportive negative emotion socialization behaviors. Specifically, African American parents who reported experiencing higher levels of racial discrimination also reported higher beliefs that 
negative emotions are costly/dangerous, which predicted higher levels of unsupportive responses (i.e., punishing, neglecting, overriding) to their child's negative affect $(\beta=.11,90 \% \mathrm{CI}=.09, .14$, $p=.000)$. Unexpectedly however, this indirect effect was significant for supportive negative emotion socialization behaviors as well. Specially, African American parents' experiences with racial discrimination predicted higher beliefs that negative emotions are costly/dangerous, which predicted higher levels of supportive responses to their child's negative affect $(\beta=.20,90 \% \mathrm{CI}=$ $.01, .03, p=.007)$

\section{Discussion}

The goal of the current study was to examine the role that perceived racial discrimination experiences has on African American parents' racial and emotional socialization behaviors. The findings indicated that African American parents' racial discrimination experiences predicted racial socialization behaviors as well as both positive and negative emotion socialization behaviors. Specifically, racial discrimination experiences predicted both effective and ineffective emotion socialization and racial socialization strategies in some expected ways (e.g., higher racial discrimination experiences predicted greater racial socialization and unsupportive negative emotion socialization) and unexpected ways (e.g., higher racial discrimination experiences predicted greater negative messages and unsupportive positive emotion socialization). This study is the first to test the association between African Americans racial discrimination experiences and their parental emotion socialization behaviors. To better understand associations between racial discrimination experiences and emotion socialization, the study further advanced the literature by testing and finding evidence that emotional beliefs served as a mediating factor between racial discrimination and emotion socialization behaviors. Overall, this study highlights the importance of African Americans' history with racial discrimination and its potential to 
impact how they think about emotions and socialize their children's emotion regulation and racial identity.

\section{Racial Discrimination and Racial Socialization}

It was hypothesized (i.e., hypothesis 1a) that parents who reported experiencing higher levels of racial discrimination would report higher levels of racial socialization behaviors. The current study corroborated previous research and found that African American parents' racial discrimination experiences were related to various racial socialization behaviors. Specifically, greater racial discrimination experienced by African American parents were associated with promoting more racial barrier messages (e.g., increase child's awareness of discrimination and ways to cope) and engaging in more socialization behaviors (e.g., promoting racial traditions), which is consistent with previous research (Hughes, 2003). African American parents experience with racial discrimination influences the way they believe their child will experience discrimination, and thus feel obligated to give their children the necessary techniques to deal with these stressors (Hughes, 2003; Hughes \& Chen, 1997). Due to African American parents experiencing racial barriers first handedly, it is not surprising that they teach their children about these racial barriers to prepare their children for potential discrimination experiences. Additionally, African American parents who experience more racial discrimination may hold the belief that society does not respect their race. Because African American parents know they cannot depend on society to help boost their child's racial self-identity and/or self-esteem, these parents they may engage in more racial socialization behaviors such as celebrating Kwanzaa or taking their child to an African American history museum to boost their child's racial identity. This study corroborated previous research highlighting the idea that African American parents' experience with racial discrimination can lead to more effective racial socialization behaviors. 
However, the current study also found that African Americans who reported more frequent racial discrimination promoted less effective racial socialization behaviors. Specifically, African American parents who experienced racial discrimination promoted less self-worth messages (e.g., prioritize individual worth outside of their race) and racial pride messages (e.g., emphasizing Black unity) with their children. These findings contradict previous research that greater racial discrimination experiences are associated with more positive racial socialization behaviors, such as more racial pride (Hughes \& Johnson, 2001). These inconsistent findings may be due to with the variation and the degree in which these African American parents are experiencing racial discrimination. For example, the scale used to measure racial discrimination in the current study only assessed the frequency and severity in which an individual experienced discrimination this year and also in their entire life. Other scales assessing racial discrimination often fail to account for individuals that experience racial discrimination more frequently and does not differentiate higher levels of racial discrimination (e.g., everyday vs. few times a year). When examining other studies who used the same racial discrimination measure as the current study (i.e., Schedule of Racist Events), the current study's mean of the sum of racial discrimination experiences in the past year $(M=59.57)$ and lifetime $(M=63.16)$ are far higher than the racial discrimination means in Landrine and Klonoff's study (1996) that validated the measure $($ Past year mean $=40.99$; Lifetime mean= 53.93 $)$ and in Greer's study $(2010$; Past year mean $=32.63 ;$ Lifetime mean $=41.22$ ). Thus, it may be the case that the current sample is experiencing higher rates of racial discrimination than previous research samples, which in turn is leading to more negative racial socialization behavior.

Similarly, it was hypothesized (i.e., hypothesis $1 \mathrm{~b}$ ) that parents experiencing higher levels of racial discrimination would report lower levels of negative messages. However, the 
current study found that African American parents who experienced greater racial discrimination were more likely to express negative messages regarding African Americans (e.g., reinforce negative stereotypes regarding African Americans) to their children. Although understudied, these findings corroborate the results in one other research study that found that African American parents who experienced racial discrimination reported expressing negative messages to their child (White-Johnson et al. 2010). Researchers have speculated that African American parents who express more negative message to their children lack a strong racial identity (Thomas \& Speight, 1999). Thus, it may be the case that African American parents who are constantly experiencing racial discrimination learn to devalue their own race, lose their racial identity, and start to hold negative attitudes regarding their race that they then teach/express to their child. There is limited research on how parent's history of racial discrimination may impact how they teach their child about race, but longitudinal research is needed to give insight into the direction of effects.

\section{Racial Discrimination Predicts Unsupportive Positive Emotion Socialization Behaviors}

It was hypothesized (i.e., hypothesis 2a) that parents who report experiencing higher levels of discrimination would report higher levels of supportive responses to their child's positive emotions. Although previous research has found that African American parents are more likely to respond in supportive ways to their child's positive emotions than other racial groups (e.g., McKee et al., 2015), conversely, the current study found that greater experiences with racial discrimination predicted parents' use of more unsupportive positive emotion socialization behaviors (e.g., punish and neglect). However, African American parents' experience of greater racial discrimination was unrelated to more supportive positive emotion socialization behaviors (e.g., reward, magnify, override). In the current study, positive emotions included pride and 
happiness to examine if parents' reactions were specific to particular types of positive emotions (e.g., unsupportive of pride but not happiness or vice versa). However, associations with parents' experience of racially discrimination were generally the same across these two different positive emotions (see Table 6). Taken together, although African American parents tend to help their children experience more positive emotions compared to other parents (e.g., McKee et al., 2015), the current study suggests this pattern is not further enhanced in parents who have experience a lot of racial discrimination.

Similar to engaging in unsupportive negative emotion socialization behaviors, African American parents may also be engaging in unsupportive reactions to children's positive emotions because they believe their children may experience negative consequences for expressing positive emotions. For a minority to successfully interact with the majority in society, African American parents believe it is imperative that their child have obedience and compliance (Kelly, Power, \& Wimbush, 1992). African American parents may be dismissing and punishing their child's positive emotions to help children cope with the possible negative consequences they will receive from society. Additionally, when it comes to parenting styles, African American parents typically score lower on sensitivity and higher on control than White parents (Berlin et al., 2002). This parenting trend is consistent with African Americans' views of creating an adaptive culture (i.e., valuing emotional self-control and limiting self-disclosure; Consedine \& Magai, 2002) for their child, and these views may become more harsher the more racial discrimination African American parents had experienced. African Americans parents' constant experience with racial discrimination may be related to more unsupportive responses to their child's positive emotions because being highly controlling of children's behavior and less sensitive to children's positive 
emotions may allow children to adapt to the harsh environment of society (e.g., racism and discrimination) and prepare them for racial adversities.

\section{Racial Discrimination Predicting Positive Emotional Beliefs}

It was hypothesized (i.e., hypothesis 3a) that parents who report experiencing higher levels of racial discrimination would report higher levels of valuing their child's positive emotions. This hypothesis was not supported. This relationship was not significant for valuing positive emotions, such that, African Americans who reported experiencing more racial discrimination was not significantly associated with greater beliefs of valuing positive emotions. Additionally, it was hypothesized (i.e., hypothesis $3 b$ ) that parents who report experiencing higher levels of racial discrimination would report lower levels of the belief that positive emotions are costly/dangerous. This hypothesis was not supported and the opposite relationship was found. Specifically, the more African American parents experienced racial discrimination, the more likely they held the belief that positive emotions were costly/dangerous to express. These results contradict research on African American positive emotional beliefs indicating that African Americans are more likely to value authentic expression of their child's positive emotions, even when the emotion was intense as compared to White parents (e.g., Parker et al., 2012). However, previous studies that examined African Americans' emotional beliefs failed to consider the possible impact of parents' racial discrimination experiences. Thus, African Americans who experience high levels of racial discrimination may start to acquire more negative emotional beliefs, even about positive emotions.

\section{Positive Emotional Beliefs Mediated Discrimination and Positive Emotion Socialization}

It was hypothesized (i.e., hypothesis 4b) that parents who reported experiencing higher levels of racial discrimination would report lower levels of the belief that positive emotions are 
costly/dangerous, which would be associated with higher levels of supportive responses to their child's positive emotions. This hypothesis was not supported in the expected direction. However, positive emotional beliefs did mediate the association between African American parents' racial discrimination experiences and their positive emotion socialization behaviors. Specifically, the more African American parents experienced racial discrimination, the greater their beliefs that positive emotions are costly/dangerous, which in turn was associated with higher levels or unsupportive responses (i.e., punish and neglect) to their child's positive emotions but not supportive responses (i.e., reward, override, magnify). This mediation finding provides support that the relationship between racial discrimination experiences and positive emotion socialization behaviors can be explained through parents' positive emotional beliefs. Unsupportive positive emotion socialization behaviors are related to negative child outcomes such as depression (e.g., Ravel et al., 2019; Katz et al., 2014; Yap et al., 2008). Thus, knowing that racial discrimination leads to greater beliefs that positive emotions are dangerous/costly to express, which in turn relates to more unsupportive responses, indicates that there could be further harmful effects of parents' experience of discrimination in that it impacts how they respond to their children's positive emotions. Future research should further examine altering emotional beliefs and emotion socialization as a point of intervention to help parents who have had continuous experiences with racial discrimination.

\section{Racial Discrimination Predicts Negative Emotion Socialization Behaviors}

Supportive negative emotion socialization. It was hypothesized (i.e., hypothesis 5a) that racial discrimination would be related to lower supportive negative emotion socialization. Unexpectedly, higher rates of racial discrimination experiences predicted greater supportive negative emotion socialization behaviors (e.g., reward and override) in African American 
parents. Rewarding negative affect consists of comforting, assisting, and/or empathizing with a child's negative emotions. Overriding negative emotions consists of distracting the child's negative emotions (e.g., buying them something). Although the research on overriding NA have been mixed, the combination of rewarding and overriding NA have been related to positive outcomes for children (Garside \& Klimes-Dougan, 2002), and these socialization behaviors can be useful when raising an African American child to deal with racial discrimination. As previously stated, African American parents who experience discrimination are likely to anticipate that their child will also experience it, and thus may feel obligated to provide their children with strategies to cope (Hughes, 2003; Hughes \& Chen, 1997). For example, Dow (2016) interviewed African American mothers and found that they encouraged their children to engage in activities such as yoga, karate, and meditation, in hopes that this emotional control would translate to interactions with their teachers, police officers, peers, and the public. Therefore, it is possible that African American parents who experience high levels of racial discrimination engage in more supportive negative emotion socialization behaviors to help children cope with the possible negative consequences of racial discrimination in society. A recent study by English and colleagues (2020) indicated that parents' efforts to help children cope with racism are needed. Specifically, African American adolescents reported an average of over five experiences of racial discrimination per day. Due to the mix findings linking parents' discrimination to both unsupportive and supportive emotion socialization strategies, it is important for future research to examine these constructs using a person-centered approach to better understand the variation of negative emotion socialization strategies being utilized and its and its potential effects on the child. 
Unsupportive negative emotion socialization. It was hypothesized (i.e., hypothesis 5b) that higher levels of racial discrimination would be associated with higher levels of unsupportive responses to their child's negative emotions. As predicted, more experience with racial discrimination was linked to more unsupportive negative emotion socialization behaviors (i.e., punishing, neglecting, magnifying). As previous research has shown, compared to other racial groups, African American parents are likely to respond more harshly and dismissively to their child's negative emotions (Halberstadt, Craig, Lozada, \& Brown, 2011; Nelson, Leerkes, O’Brien, Calkins, \& Marcovitch, 2012; Parker et al., 2012). These unsupportive behaviors by African American parents can be due to the fact that African American children face more discrimination from the majority culture when exhibiting negative emotions (Kang \& Chasteen, 2009; Stevenson et al., 2002). For example, in an experiment viewing the expression of anger in Whites and African Americans, participants were more likely to view African Americans' anger expression as more aggressive and threatening than the expression of anger in Whites (Kang \& Chasteen, 2009). Additionally, African American boys face harsher discipline in school and are labeled aggressive and violent more often than their White classmates (Eitle \& Eitle 2004; Ferguson 2000; Morris, 2007). Parents adapt their parenting behaviors to help their child cope with specific stressors (e.g., racism/discrimination) in their life. Thus, the negative consequences their children receive from society when expressing negative emotions may help shape African American parenting behaviors (e.g., rejecting/punishing their child's negative emotions). As a novel extension of these studies that have focused on children's experience of discrimination, this study found that African American parents' experiences with racial discrimination additionally predicts their parenting behaviors. 
Again, researchers speculate that African American parents who experience high levels of racial discrimination experiences assume their child will likely experience discrimination as well (Hughes, 2003). Thus, they may engage in strategies that downregulate negative emotions to protect their children. One study found that when discussing discrimination with their sons, African American mothers discouraged their sons to respond to discrimination in the moment and hide their negative emotions to be better received by the public (Dow, 2016). Although these emotion socialization behaviors may appear to be maladaptive or unsupportive, African American parents experiencing high rates of racial discrimination may engage in these negative emotion socialization behaviors in an to attempt to teach their child to combat and better cope with the possible racial stressors they will experience in society.

\section{Racial Discrimination Predicting Negative Emotional Beliefs}

It was also hypothesized (i.e., hypothesis 6a) that parents who report experiencing higher levels of racial discrimination would report lower levels of valuing their child's negative emotions. This hypothesis was unsupported, the results were significant in the opposite direction, such that greater racial discrimination experiences reported by African American parents was associated with greater beliefs of valuing their child's negative emotions. Valuing negative emotions include the belief that negative emotions are useful and that expressing negative emotions can motivate or fix something. Although it may appear contradictory that parents can have both the beliefs that negative emotions can be costly and/or dangerous and that negative emotions are important to value, these beliefs may not be mutually exclusive. African American parents who experience higher levels of racial discrimination may feel as though their negative emotions are devalued in society and therefore costly to express. Yet, they may still believe that 
their child's negative emotions should be valued, even though their own emotions may not be in the larger society.

It was also hypothesized (i.e., hypothesis 6b) that parents who report experiencing higher levels of racial discrimination would report higher levels of the belief that negative emotions are costly/dangerous. The current study supported this hypothesis such that, the more African American parents reported experiencing racial discrimination, the more likely they held the belief that negative emotions were dangerous/costly for their child to express. This finding is congruent with research on African Americans' negative emotional beliefs and expression. African Americans often value emotional self-control and limit their self-disclosure (Consedine \& Magai, 2002; Plasky \& Lorion, 1984). These values are thought to help African Americans become less reactive to negativity and more reserved, which could potentially make them less vulnerable to racial discrimination experiences and stereotypes. It is speculated that African American parents' beliefs that negative emotions are dangerous/costly for their child to express, can be attributed to their racial discrimination experiences and negative consequences expressing negative emotions (e.g., stereotyped or labeled as the "angry black woman/man;" Nelson et al., 2012).

\section{Negative Emotional Beliefs Mediated Discrimination and Negative Emotion Socialization}

Hypothesis 7a, that higher levels of racial discrimination, would relate to lower levels of valuing children's negative emotions, which in turn predict higher levels of unsupportive negative emotion socialization behaviors, was not supported. However, Hypothesis $7 \mathrm{~b}$ that parents who report experiencing higher levels of discrimination would endorse more beliefs that negative emotions are costly/dangerous, which in turn predict higher levels of unsupportive responses to their child's negative emotions, was supported. African American parents who 
experienced greater racial discrimination, had greater beliefs that expressing negative emotions were costly/dangerous, which predicted higher levels of unsupportive responses (i.e., punishing, neglecting, magnify). Unexpectedly, racial discrimination and greater beliefs that negative emotions are costly/dangerous also predicted more supportive responses (i.e., reward and override) to their child's negative affect. Overall, these mediated findings provide novel empirical support for conceptual models of parental socialization of children's emotion, suggesting that parents' beliefs about emotions may motivate how they respond to their children's emotions (e.g., Eisenberg et al., 1998). Yet, the findings are also less intuitive because African American parents who held the belief that negative emotions were costly/dangerous still engaged in supportive negative emotion socialization strategies such as rewarding and coaching their child's negative emotions. Prior research sometimes has found that emotional beliefs are not always associated with parents' emotion socialization behaviors (Wong, McElwain, \& Halberstadt, 2009). This study provides some nuanced information in that thinking negative emotions may be dangerous may still be linked to being supportive and accepting of their child's negative emotions. These mixed findings may be due to the contextual demand. Eisenberg, Cumberland, and Spinrad's heuristic model (1998) of emotion socialization includes the context playing a role in emotion-related parenting practices. Similarly, African Americans are more open to expressing negative emotions privately around their African American friends and family (Jackson \& Wingfield 2013). Therefore, African American parents may use more supportive negative emotion socialization behaviors at home and more unsupportive emotion socialization behaviors out in public. Due to emotional beliefs (e.g. negative emotions are costly/dangerous) mediating the association between both supportive and unsupportive negative 
emotion socialization it is imperative that future studies further examine the context to better understand the specific factors that may influence emotion socialization behaviors.

\section{Strengths, Limitations and Future Directions}

The current study provides novel findings to research on racial discrimination and emotion socialization behaviors. Although previous studies have examined the role that racial discrimination has on racial socialization behaviors (e.g., Neblett et al., 2008; Neblett Jr. et al., 2006; White-Johnon \& Seller, 2010), this research has been limited in its sample (e.g., low income mothers) and fails to include other parenting behaviors (e.g., emotion socialization). Thus, this study helps expand the sparse research on African Americans' racial socialization behaviors. Lastly, this is the first study to examine the role racial discrimination has on African American's positive and negative emotion socialization behaviors, and further, to test whether emotional beliefs mediate the association between racial discrimination experiences and emotion socialization behaviors.

However, the strengths in the study should be considered in light of its limitations. One limitation is that all of the measures in the study were collected via Amazon Mturk which is susceptible to selection bias (e.g., participants have to have internet access, have access to computer, tech savvy, etc.) and were self-reported, which is susceptible to social desirability bias. Although various measures were taken to ensure valid responses (e.g., validity checks), participants could have falsified data or over/under-reported on their parenting behaviors. Research has found that more reliable methods in assessing parenting behaviors is informant reporting (e.g., child, spouse; Morsbach \& Prinz, 2006) or observational measures (Scott et al., 2011). Thus, future studies should utilize informant reporting to ensure the results remain consistent. Another limitation is that the current study utilized data at one time point, therefore 
causal inferences cannot be made. Future studies should examine racial discrimination and African American parents' socialization behavior longitudinally to determine the temporal order and potential bidirectionality of these associations and examine whether these results hold true over time.

There was great diversity in the sample such that the participants were from over 40 states across the U.S, from counties ranging in the percentage of African Americans (0-92\%). The sample was also diverse in terms of age, sex, and income. However, although parents could have a child anywhere between 8 and 18 years of age, many parents (54\%) completed their survey in relation to one of their children between the ages of 8 and 9 years old. It would have been useful to have more data collected on parents' socialization behavior on their older children, since child's age greatly influences parental socialization behaviors (Dix, 1991; Klimes-Dougan et al., 2007; O’Neal \& Malatesta-Magai, 2005). Thus, future studies should examine these constructs with a more stratified sample to better understand the role of children's age given that socialization pertaining to emotion expression or race could vary by children's age (e.g., O’Neal \& Malatesta-Magai, 2005). Furthermore, the current study only examined African American participants. Other racial and ethnic minorities (e.g., Asians, Hispanics, etc.) are affected by discrimination (e.g., Lee, Perez, Boykin \& Mendoza-Denton, 2019) and these discrimination experiences can also influence their parenting behavior (Morelen \& Thomassin, 2013). Therefore, future studies should examine whether these results can be corroborated with other racial and ethnic groups in order to generalize the results to a wider audience.

Lastly, the current study took a variable centered approach which makes it difficult to fully understand all the findings from the study. There were many mixed findings. For example, racial discrimination was related to both supportive and unsupportive emotion socialization 
behaviors, effective and ineffective racial socialization behaviors, and contradictory emotional beliefs (e.g., beliefs that negative emotions are dangerous however value negative emotion). Therefore, it is imperative that future research examine these constructs using a person-centered approach. Parents rarely, if ever, display/convey a single emotion or racial socialization message to their child. Socialization behaviors (i.e., racial and emotional) are often transmitted in combinations. A person-centered approach will help research view differences in the patterning of numerous racial socialization messages across people to better understand the current studies opposing results.

\section{Conclusion}

Overall, despite its limitations, the current study highlights the importance of considering the role that racial discrimination has on parents' emotion socialization behaviors. The study found that greater racial discrimination experienced by African American parents not only predicted unsupportive emotion socialization behaviors but also supportive emotion socialization behaviors. Therefore, indicating that the experiences with racial discrimination does not hinder every aspect of parenting and that these racial discrimination experience can help the parents foster more supportive responses to their child's positive and negative emotions. Additionally, this study was the first to provide evidence that beliefs about emotions mediates the relationship between racial discrimination and parental emotion socialization behaviors. African American parents' racial discrimination experiences shape their emotional beliefs which predicts their emotion socialization behaviors.

This study establishes an initial step in the examination of racial discrimination experiences and parental emotion socialization behaviors. However, children's outcomes should be further examined. Parental socialization behaviors have been shown to influence children's 
emotion regulation and their well-being and problem behaviors (e.g., Eisenberg et al., 1999, Lagace-Seguin \& Coplan, 2005; Stoolmiller et al., 2003; Yi et al., 2016). Better understanding and helping parents improve their socialization and parenting behaviors, could possibly improve their child's overall social and emotional well-being. Knowing that racial discrimination can impact a parent's socialization behaviors, clinicians should help parents experiencing high levels of racial discrimination cope with these stressors, in hopes that the parents' social or emotional traumas does not impact their children negatively. Thus, it is imperative to further study parents' racial discrimination experiences from all different races/ethnicities and examine its influence on parenting behaviors for intervention purposes. 


\section{References}

Anderson, R. E., Hussain, S. B., Wilson, M. N., Shaw, D. S., Dishion, T. J., \& Williams, J. L. (2015). Pathways to Pain: Racial Discrimination and Relations Between Parental Functioning and Child Psychosocial Well-Being. The Journal of Black Psychology, 41, 491-512. doi:10.1177/0095798414548511

Barnes, L. L., De Leon, C. F. M., Lewis, T. T., Bienias, J. L., Wilson, R. S., \& Evans, D. A. (2008). Perceived discrimination and mortality in a population-based study of older adults. American Journal of Public Health, 98, 1241-1247.

doi:10.2105/AJPH.2007.114397

Belsky, J. (1984). The determinants of parenting: A process model. Child Development, 55, 8396. doi:10.2307/1129836

Benner, A. D., \& Kim, S. Y. (2009). Experiences of discrimination among Chinese American adolescents and the consequences for socioemotional and academic development. Developmental Psychology, 45, 1682-1694. doi:10.1037/a0016119

Berinsky, A. J., Huber, G. A., \& Lenz, G. S. (2012). Evaluating online labor markets for experimental research: Amazon. com's Mechanical Turk. Political Analysis, 20, 351-368. doi:10.1093/pan/mpr057

Bijttebier, P., Raes, F., Vasey, M. W., \& Feldman, G. C. (2012). Responses to positive affect predict mood symptoms in children under conditions of stress: A prospective study. Journal of Abnormal Child Psychology, 40, 381-389. doi:10.1007/s10802-0119579-2 
Boomsma, A. (1985). Nonconvergence, improper solutions, and starting values in LISREL maximum likelihood estimation. Psychometrika, 50, 229-242. doi:10.1007/BF02294248

Bowman, P. J., \& Howard, C. (1985). Race-related socialization, motivation, and academic achievement: A study of Black youths in three-generation families. Journal of the American Academy of Child Psychiatry, 24, 134-141. doi:10.1016/S00027138(09)60438-6

Boykin, A. W. (1986). The triple quandary and the schooling of Afro-American children. The School Achievement of Minority Children: New Perspectives, 7- 92. London: Lawrence Erlbaum.

Boykin, A. W., \& Toms, F. D. (1985). Black child socialization: A conceptual framework. Black Children: Social, Educational, and Parental Environments, 33-51. Thousand Oaks, CA: Sage.

Briscoe, C., Stack, D. M., Dickson, D. J., \& Serbin, L. A. (2019). Maternal Emotion Socialization Mediates the Relationship between Maternal and Adolescent Negative Emotionality. Journal of Youth and Adolescence, 48, 495-509. doi:10.1007/s10964-0180945-Z

Brody, G. H., Chen, Y. F., Kogan, S. M., Murry, V. M., Logan, P., \& Luo, Z. (2008). Linking perceived discrimination to longitudinal changes in African American mothers' parenting practices. Journal of Marriage and Family, 70, 319-331. doi:10.1111/j.17413737.2008.00484.x 
Brondolo, E., Ver Halen, N. B., Pencille, M., Beatty, D., \& Contrada, R. J. (2009). Coping with racism: A selective review of the literature and a theoretical and methodological critique. Journal of Behavioral Medicine, 32, 64-88. doi:10.1007/s10865-008-9193-0

Bryant, F. (2003). Savoring Beliefs Inventory (SBI): A scale for measuring beliefs about savouring. Journal of Mental Health, 12, 175-196. doi:10.1080/0963823031000103489

Buhrmester, M., Kwang, T., \& Gosling, S. D. (2011). Amazon's Mechanical Turk: A new source of inexpensive, yet high-quality, data?. Perspectives on Psychological Science, 6, 3-5. doi:10.1177/1745691610393980

Caughy, M. O. B., O’Campo, P. J., Randolph, S. M., \& Nickerson, K. (2002). The influence of racial socialization practices on the cognitive and behavioral competence of African American preschoolers. Child Development, 73, 1611-1625. doi: 10.1111/14678624.00493

Clark, R., Anderson, N. B., Clark, V. R., \& Williams, D. R. (1999). Racism as a stressor for African Americans: A biopsychosocial model. American Psychologist, 54, 805-816. doi:10.1037/0003-066X.54.10.805.

Clavél, F. D., Cutrona, C. E., \& Russell, D. W. (2017). United and divided by stress: How stressors differentially influence social support in African American couples over time. Personality and Social Psychology Bulletin, 43, 1050-1064. doi:10.1177/0146167217704195

Coard, S. I., \& Sellers, R. M. (2005). African American families as a context for racial socialization. African American Family Life: Ecological and Cultural Diversity, 264-284. New York, NY: Guilford Press. 
Cole, M. P., \& Tan, Z. P. (2007). Emotion socialization from a cultural perspective, Handbook of Socialization: Theory and Research, 516-542. New York, NY: Guilford Press.

Conger, R. D., \& Donnellan, M. B. (2007). An interactionist perspective on the socioeconomic context of human development. Annual. Review Psychology, 58, 175-199. doi: 10.1146/annurev.psych.58.110405.085551

Consedine, N. S., \& Magai, C. (2002). The uncharted waters of emotion: Ethnicity, trait emotion and emotion expression in older adults. Journal of Cross-Cultural Gerontology, 17, 71100. doi:10.1023/A:1014838920556F

Constantine, M. G., \& Blackmon, S. K. M. (2002). Black adolescents' racial socialization experiences: Their relations to home, school, and peer self-esteem. Journal of Black Studies, 32, 322-335. doi:10.1177/002193470203200303

Deitch, E. A., Barsky, A., Butz, R. M., Chan, S., Brief, A. P., \& Bradley, J. C. (2003). Subtle yet significant: The existence and impact of everyday racial discrimination in the workplace. Human Relations, 56, 1299-1324. doi:10.1177/00187267035611002

Derogatis, L. R., Lipman, R. S., Rickels, K., Uhlenhuth, E. H., \& Covi, L. (1974). The Hopkins Symptom Checklist (HSCL): A self-report symptom inventory. Behavioral Science, 19, 1-15. doi:10.1002/bs.3830190102

Diener, E. D., Emmons, R. A., Larsen, R. J., \& Griffin, S. (1985). The satisfaction with life scale. Journal of Personality Assessment, 49, 71-75. doi:10.1.1.470.1157 
Dix, T. (1992). Parenting on behalf of the child: Empathic goals in the regulation of responsive parenting. Parental Belief Systems: The Psychological Consequences for Children, 319346. Hillsdale, NJ: Lawrence Erlbaum Associates.

Dow, D. M. (2016). The deadly challenges of raising African American boys: Navigating the controlling image of the "thug". Gender \& Society, 30, 161-188. doi: $10.1177 / 0891243216629928$

Dunbar, A. S., Leerkes, E. M., Coard, S. I., Supple, A. J., \& Calkins, S. (2017). An integrative conceptual model of parental racial/ethnic and emotion socialization and links to children's social-emotional development among African American families. Child Development Perspectives, 11, 16-22. doi:10.1111/cdep.12218

Dunsmore, J. C., Her, P., Halberstadt, A. G., \& Perez-Rivera, M. B. (2009). Parents’ beliefs about emotions and children's recognition of parents' emotions. Journal of Nonverbal Behavior, 33, 121-140. doi:10.1007/ s10919-008-0066-6

Eisenberg, N., Cumberland, A., \& Spinrad, T. L. (1998). Parental socialization of emotion. Psychological Inquiry, 9, 241-273. doi:10.1207/s15327965pli0904_17

Eisenberg, N., Fabes, R. A., Shepard, S. A., Guthrie, I. K., Murphy, B. C., \& Reiser, M. (1999). Parental reactions to children's negative emotions: Longitudinal relations to quality of children's social functioning. Child Development, 70, 513-534. doi:10.1111/14678624.00037

English, D., Lambert, S. F., Tynes, B. M., Bowleg, L., Zea, M. C., \& Howard, L. C. (2020). Daily multidimensional racial discrimination among Black US American adolescents. Journal of Applied Developmental Psychology, 66. doi:101068 
Fabes, R. A., Leonard, S. A., Kupanoff, K., \& Martin, C. L. (2001). Parental coping with children's negative emotions: Relations with children's emotional and social responding. Child Development, 72, 907-920. doi:10.1111/1467-8624.00323

Feldman, G. C., Joormann, J., \& Johnson, S. L. (2008). Responses to positive affect: A selfreport measure of rumination and dampening. Cognitive Therapy and Research, 32, 507. doi: 10.1007/s10608-006-9083-0

Fischer, A. R., \& Shaw, C. M. (1999). African Americans' mental health and perceptions of racist discrimination: The moderating effects of racial socialization experiences and selfesteem. Journal of Counseling Psychology, 46, 395. doi:10.1037/0022-0167.46.3.395

Garrett-Peters, P., Mills-Koonce, R., Adkins, D., Vernon-Feagans, L., Cox, M., \& Family Life Project Key Investigators. (2008). Early environmental correlates of maternal emotion talk. Parenting: Science and Practice, 8, 117-152. doi:10.1080/15295190802058900

Garside, R. B., \& Klimes-Dougan, B. (2002). Socialization of discrete negative emotions: Gender differences and links with psychological distress. Sex Roles, 47, 115-128. doi:10.1023/A\%3A1021090904785\%I

Gentzler, A. L., Morey, J. N., Palmer, C. A., \& Yi, C. Y. (2013). Young adolescents' responses to positive events: Associations with positive affect and adjustment. The Journal of Early Adolescence, 33, 663-683. doi:10.1177/0272431612462629

Gentzler, A. L., Palmer, C. A., \& Ramsey, M. A. (2016). Savoring with intent: Investigating types of and motives for responses to positive events. Journal of Happiness Studies, 17, 937-958. doi:10.1007/s10902-015-9625-9 
Gentzler, A. L., Ramsey, M. A., \& Black, K. R. (2015). Mothers' attachment styles and their children's self-reported security, as related to maternal socialization of children's positive affect regulation. Attachment \& Human Development, 17, 376-398.

doi:10.1080/14616734.2015.1055507

Goosby, B. J., Malone, S., Richardson, E. A., Cheadle, J. E., \& Williams, D. T. (2015).

Perceived discrimination and markers of cardiovascular risk among low-income A frican A merican youth. American Journal of Human Biology, 27, 546-552.

doi:10.1002/ajhb.22683

Gottman, J. M., Katz, L. F., \& Hooven, C. (1997). Introduction to the concept of metaemotion. Meta-emotion. How Families Communicate Emotionally, 3-8. Hillsdale, NJ: Lawrence Erlbaum Associates.

Graham, S. (1992). " Most of the subjects were White and middle class": Trends in published research on African Americans in selected APA journals, 1970-1989. American Psychologist, 47, 629-639. doi:10.1037/0003-066X.47.5.629

Greer, T. M. (2010). A structural validation of the schedule of racist events. Measurement and Evaluation in Counseling and Development, 43, 91-107. doi: $10.1177 / 0272989 X 10373455$

Halberstadt, A. G., Dunsmore, J. C., Bryant Jr, A., Parker, A. E., Beale, K. S., \& Thompson, J. A. (2013). Development and validation of the Parents' Beliefs About Children's Emotions Questionnaire. Psychological Assessment, 25, 1195. doi:10.1037/a0033695 
Halberstadt, A. G., Dunsmore, J. C., McElwain, N., Eaton, K. L., \& McCool, A. (2001). Parents' beliefs about negative emotions. Unpublished questionnaire, North Carolina State University.

Halberstadt, A. G., Thompson, J. A., Parker, A. E., \& Dunsmore, J. C. (2008). Parents' emotionrelated beliefs and behaviours in relation to children's coping with the 11 September 2001 terrorist attacks. Infant and Child Development: An International Journal of Research and Practice, 17, 557-580. doi:10.1002/icd.569

Harris-Britt, A., Valrie, C. R., Kurtz-Costes, B., \& Rowley, S. J. (2007). Perceived racial discrimination and self-esteem in African American youth: Racial socialization as a protective factor. Journal of Research on Adolescence, 17, 669-682. doi:10.1111/j.15327795.2007.00540.x

Hooven, C., Gottman, J. M., \& Katz, L. F. (1995). Parental meta-emotion structure predicts family and child outcomes. Cognition \& Emotion, 9, 229-264. doi:10.1080/02699939508409010

Hudson, D. L., Neighbors, H. W., Geronimus, A. T., \& Jackson, J. S. (2016). Racial discrimination, John Henryism, and depression among African Americans. Journal of Black Psychology, 42, 221-243. doi:10.1177/0095798414567757

Hughes, D. (2003). Correlates of African American and Latino Parents' messages to children about ethnicity and race: A comparative study of racial socialization. American Journal of Community Psychology, 31, 15-33. doi:10.1023/A:1023066418688 
Hughes, D., Bachman, M. Ruble, D., \& Fuligni, A. (2006). Tuned in or tuned out: Children's interpretations of parents' racial socialization messages. Child Psychology: A Handbook of Contemporary Issues, 591-610. Philadelphia: Psychology Press.

Hughes, D., \& Johnson, D. (2001). Correlates in children's experiences of parents' racial socialization behaviors. Journal of Marriage and Family, 63, 981-995. doi:10.1111/j.1741-3737.2001.00981.x

Hughes, D., Rodriguez, J., Smith, E. P., Johnson, D. J., Stevenson, H. C., \& Spicer, P. (2006). Parents' ethnic-racial socialization practices: A review of research and directions for future study. Developmental Psychology, 42, 747-770. doi:10.1037/0012-1649.42.5.747

Hughes, D., Witherspoon, D., Rivas-Drake, D., \& West-Bey, N. (2009). Received ethnic-racial socialization messages and youths' academic and behavioral outcomes: Examining the mediating role of ethnic identity and self-esteem. Cultural Diversity and Ethnic Minority Psychology, 15, 112-124. doi:10.1037/a0015509

Kang, S. K., \& Chasteen, A. L. (2009). The moderating role of age-group identification and perceived threat on stereotype threat among older adults. The International Journal of Aging and Human Development, 69, 201-220. doi:10.2190/AG.69.3.c

Katz, L. F., \& Hunter, E. C. (2007). Maternal meta-emotion philosophy and adolescent depressive symptomatology. Social Development, 16, 343-360. doi:10.1111/j.14679507.2007.00388.x

Kehoe, C. E., Havighurst, S. S., \& Harley, A. E. (2014). Tuning in to teens: Improving parent emotion socialization to reduce youth internalizing difficulties. Social Development, 23, 413-431. doi:10.1111/sode. 12060 
Klimes-Dougan, B., Brand, A. E., Zahn-Waxler, C., Usher, B., Hastings, P. D., Kendziora, K., \& Garside, R. B. (2007). Parental emotion socialization in adolescence: Differences in sex, age and problem status. Social Development, 16, 326-342. doi:10.1111/j.14679507.2007.00387.x

Klimes-Dougan, B., Hasstings, P., Granger, D., Usher, B., Zahn-Waxler, C. (2001). Adrencortical activity in at risks and normally developing adolescents: individual differences in salivary cortisol response to social challenges, basal levels, and circadian rhythms. Development Psychopathology, 13, 695-719. doi:10.1017/S0954579401003157

Kline, R. B. (2010). Promise and pitfalls of structural equation modeling in gifted research. Methodologies for Conducting Research of Giftedness, 147-169. Washington, DC: American Psychological Association.

Krieger, N., \& Sidney, S. (1996). Racial discrimination and blood pressure: the CARDIA Study of young black and white adults. American Journal of Public Health, 86, 1370-1378. doi:10.2105/AJPH.86.10.1370

Lagacé-Séguin, D. G., \& Coplan, R. J. (2005). Maternal emotional styles and child social adjustment: Assessment, correlates, outcomes and goodness of fit in early childhood. Social Development, 14, 613-636. doi:10.1111/j.1467-9507.2005.00320.x

Landrine, H., \& Klonoff, E. A. (1996). The schedule of racist events: A measure of racial discrimination and a study of its negative physical and mental health consequences. Journal of Black Psychology, 22, 144-168. doi:10.1177/00957984960222002 
Lee, D. L., \& Ahn, S. (2013). The relation of racial identity, ethnic identity, and racial socialization to discrimination-distress: A meta-analysis of Black Americans. Journal of Counseling Psychology, 60, 1-14. doi:10.1037/a0031275

Lee, R. T., Perez, A. D., Boykin, C. M., \& Mendoza-Denton, R. (2019). On the prevalence of racial discrimination in the United States. PloS One, 14, 1-16. doi: 10.1371/journal.pone.0210698

Leerkes, E. M., Supple, A. J., Su, J., \& Cavanaugh, A. (2013). Links between childhood emotion socialization and adult well-being: Similarities and differences for African American and European American women. Journal of Family Issues, 36, 1854-1877. doi:10.1177/0192513X13505567

Lesane-Brown, C. L., Scottham, K. M., Nguyen, H. X., \& Sellers, R. M. (2006). The racial socialization questionnaire-Teen (RSQ-t): A new measure for use with African American adolescents. Unpublished manuscript, Department of Psychology, University of Michigan, Ann Arbor.

Lewis, T. T., Barnes, L. L., Bienias, J. L., Lackland, D. T., Evans, D. A., \& Mendes de Leon, C. F. (2009). Perceived discrimination and blood pressure in older African American and white adults. Journals of Gerontology Series A: Biomedical Sciences and Medical Sciences, 64, 1002-1008. doi:10.1093/gerona/glp062

Lewis, T. T., Kravitz, H. M., Janssen, I., \& Powell, L. H. (2011). Self-reported experiences of discrimination and visceral fat in middle-aged African-American and Caucasian women. American Journal of Epidemiology, 173, 1223-1231. doi:10.1093/aje/kwq466 
Lozada, F. T., Halberstadt, A. G., Craig, A. B., Dennis, P. A., \& Dunsmore, J. C. (2016). Parents' beliefs about children's emotions and parents' emotion-related conversations with their children. Journal of Child and Family Studies, 25, 1525-1538. doi:10.1007/s10826-015-0325-1

Magai, C., \& McFadden, S. H. (Eds.). (1996). Handbook of Emotion, Adult Development, and Aging. New York, NY: Guilford Press.

Magai, C., \& O’Neal, C. R. (1997). Emotions as a child (child version). Unpublished manuscript, Long Island University, Brooklyn.

Mason, W.A., \& Watts, D.J. (2009). Financial incentives and the "performance of crowds." Association for Computing Machinery Explorations Newsletter, 77-85.

Matsumoto, D. (1993). Ethnic differences in affect intensity, emotion judgments, display rule attitudes, and self-reported emotional expression in an American sample. Motivation and Emotion, 17, 107-123. doi:10.1007/BF00995188

McAdoo, H. P. (2002). African American parenting. Handbook of Parenting, 4, 47-58. Mahwah, NJ: Lawrence Erlbaum Associates Publishers.

McKee, L. G., Faro, A. L., O'Leary, J. L., Spratt, K. H., \& Jones, D. J. (2015). Socializing positive emotion: A qualitative study of African American single mothers and their adolescent youth. Family Relations, 64, 635-650. doi:10.1111/fare.12160

Moran, K. M., Root, A. E., Vizy, B. K., Wilson, T. K., \& Gentzler, A. L. (2019). Maternal socialization of children's positive affect regulation: Associations with children's 
savoring, dampening, and depressive symptoms. Social Development, 28, 306-322. doi: $10.1111 /$ sode. 12338

Morelen, D., \& Thomassin, K. (2013). Emotion socialization and ethnicity: An examination of practices and outcomes in African American, Asian American, and Latin American families. The Yale Journal of Biology and Medicine, 86, 168-178.

Morey, J. N., \& Gentzler, A. L. (2017). Parents' perceptions of and responses to children’s emotions: Relations with meta-emotion philosophy and adult attachment. Parenting: Science and Practice, 17, 73-103. doi:10.1080/15295192.2017.1304782

Morsbach, S. K., \& Prinz, R. J. (2006). Understanding and improving the validity of self-report of parenting. Clinical Child and Family Psychology Review, 9, 1-21. doi: 10.1007/s10567-006-0001-5

Murry, V. M., Brody, G. H., Simons, R. L., Cutrona, C. E., \& Gibbons, F. X. (2008). Disentangling ethnicity and context as predictors of parenting within rural African American families. Applied Development Science, 12, 202-210. doi:10.1037/00121649.39.3.430

Neblett, E. W., Smalls, C. P., Ford, K. R., Nguyen, H. X., \& Sellers, R. M. (2009). Racial socialization and racial identity: African American parents' messages about race as precursors to identity. Journal of Youth and Adolescence, 38, 189-203. doi:10.1007/s10964-008-9359-7

Neblett Jr, E. W., Banks, K. H., Cooper, S. M., \& Smalls-Glover, C. (2013). Racial identity mediates the association between ethnic-racial socialization and depressive 
symptoms. Cultural Diversity and Ethnic Minority Psychology, 19, 200-207.

doi:10.1037/a0032205

Neblett Jr, E. W., Chavous, T. M., Nguyên, H. X., \& Sellers, R. M. (2009). " Say It Loud—I'm Black and I'm Proud": Parents' Messages about Race, Racial Discrimination, and Academic Achievement in African American Boys. The Journal of Negro Education, 246-259.

Neblett Jr, E. W., Philip, C. L., Cogburn, C. D., \& Sellers, R. M. (2006). African American adolescents' discrimination experiences and academic achievement: Racial socialization as a cultural compensatory and protective factor. Journal of Black psychology, 32, 199218. doi: $10.1177 / 0095798406287072$

Neblett Jr, E. W., White, R. L., Ford, K. R., Philip, C. L., Nguyen, H. X., \& Sellers, R. M. (2008). Patterns of racial socialization and psychological adjustment: Can parental communications about race reduce the impact of racial discrimination?. Journal of Research on Adolescence, 18, 477-515. doi:10.1111/j.1532-7795.2008.00568.x

Nelson, J. A., Leerkes, E. M., O'Brien, M., Calkins, S. D., \& Marcovitch, S. (2012). African American and European American mothers' beliefs about negative emotions and emotion socialization practices. Parenting, 12, 22-41. doi:10.1080/15295192.2012.638871

Nelson, J. A., Leerkes, E. M., Perry, N. B., O'Brien, M., Calkins, S. D., \& Marcovitch, S. (2013). E uropean-A merican and A frican-A merican Mothers' Emotion Socialization Practices Relate Differently to Their Children's Academic and Social-emotional Competence. Social Development, 22, 485-498. doi:10.1111/j.1467-9507.2012.00673.x 
O'Neal, C. R., \& Magai, C. (2005). Do parents respond in different ways when children feel different emotions? The emotional context of parenting. Development and Psychopathology, 17, 467-487. doi:10.1017/S0954579405050224

Parker, A. E., Halberstadt, A. G., Dunsmore, J. C., Townley, G., Bryant, A., Thompson, J. A., \& Beale, K. S. (2012). Emotions are a window into one's heart: A qualitative analysis of parental beliefs about children's emotions across three ethnic groups. Monographs for the Society for Research in Child Development, 77, 1-136. doi:10.1111/j.15405834.2012.00678.x

Perez Rivera, M. B., \& Dunsmore, J. C. (2011). Mothers' acculturation and beliefs about emotions, mother-child emotion discourse, and children's emotion understanding in Latino families. Early Education and Development, 22, 324-354. doi:10.1080/10409281003702000

Radloff, L. S. (1977). The CES-D scale: A self-report depression scale for research in the general population. Applied Psychological Measurement, 1, 385-401. doi:10.1177/ 014662167700100306

Rindskopf, D. (1984). Using phantom and imaginary latent variables to parameterize constraints in linear structural models. Psychometrika, 49, 37-47. doi:10.1007/BF02294204

Rogers, M. L., Halberstadt, A. G., Castro, V. L., MacCormack, J. K., \& Garrett-Peters, P. (2016). Maternal emotion socialization differentially predicts third-grade children's emotion regulation and lability. Emotion, 16, 280. doi:10.1037/emo0000142 
Russell, D. W., Clavél, F. D., Cutrona, C. E., Abraham, W. T., \& Burzette, R. G. (2018). Neighborhood racial discrimination and the development of major depression. Journal of Abnormal Psychology, 127, 150. doi:10.1037/abn0000336

Sanders, W., Zeman, J., Poon, J., \& Miller, R. (2015). Child regulation of negative emotions and depressive symptoms: The moderating role of parental emotion socialization. Journal of Child and Family Studies, 24, 402-415. doi:10.1007/s10826-013-9850-y

Scott, S., Briskman, J., \& Dadds, M. R. (2011). Measuring parenting in community and public health research using brief child and parent reports. Journal of Child and Family Studies, 20, 343-352. doi:10.1007/s10826-010-9398-z.

Sellers, R. M., Copeland-Linder, N., Martin, P. P., \& Lewis, R. L. H. (2006). Racial identity matters: The relationship between racial discrimination and psychological functioning in African American adolescents. Journal of Research on Adolescence, 16, 187-216. doi: 10.1111/j.1532-7795.2006.00128.x

Smith, M., \& Walden, T. (2001). An exploration of African American preschool-aged children's behavioral regulation in emotionally arousing situations. Child Study Journal, 31, 13-13.

Snyder, J., Stoolmiller, M., Wilson, M., \& Yamamoto, M. (2003). Child anger regulation, parental responses to children's anger displays, and early child antisocial behavior. Social Development, 12, 335-360. doi:10.1111/1467-9507.00237

Spencer, M. B. (1983). Children's cultural values and parental child rearing strategies. Developmental Review, 3, 351-370. doi:10.1016/0273-2297(83)90020-5 
Spielberger, C. D. (1985). The experience and expression of anger: Construction and validation of an anger expression scale. Anger and Hostility in Cardiovascular and Behavioral Disorders, 5-30. New York, NY: Hemisphere.

Stevenson Jr, H. C., Cameron, R., Herrero-Taylor, T., \& Davis, G. Y. (2002). Development of the teenager experience of racial socialization scale: Correlates of race-related socialization frequency from the perspective of Black youth. Journal of Black Psychology, 28, 84-106. doi:10.1177/0095798402028002002

Sutton, T. E., Gordon Simons, L., Martin, B. T., Klopack, E. T., Gibbons, F. X., Beach, S. R., \& Simons, R. L. (2019). Racial discrimination as a risk factor for African American men's physical partner violence: A longitudinal test of mediators and moderators. Violence Against Women, 1, 1-27. doi:1077801219830245.

Thornton, M. C., Chatters, L. M., Taylor, R. J., \& Allen, W. R. (1990). Sociodemographic and environmental correlates of racial socialization by Black parents. Child Development, 61, 401-409. doi:10.2307/1131101

Tillery, R., Cohen, R., Parra, G. R., Kitzmann, K. M., \& Howard Sharp, K. M. (2015). Friendship and the Socialization of Sadness. Merrill-Palmer Quarterly, 61, 486-508. doi:10.13110/merrpalmquar1982.61.4.0486

Utsey, S. O., Ponterotto, J. G., Reynolds, A. L., \& Cancelli, A. A. (2000). Racial discrimination, coping, life satisfaction, and self-esteem among African Americans. Journal of Counseling \& Development, 78, 72-80. doi:10.1002/j.1556-6676.2000.tb02562.x

Varner, F., Hou, Y., Ross, L., Hurd, N. M., \& Mattis, J. (2019). Dealing with discrimination: Parents' and adolescents' racial discrimination experiences and parenting in African 
American families. Cultural Diversity and Ethnic Minority Psychology, 1, 1-7. doi:10.1037/cdp0000281

Wang, M. T., \& Huguley, J. (2012). Parental racial socialziation as a moderator of the effects of racial discrimination on educaitonal success among African American adolescents. Child Development, 83, 1716-1731.

White-Johnson, R. L., Ford, K. R., \& Sellers, R. M. (2010). Parental racial socialization profiles: Association with demographic factors, racial discrimination, childhood socialization, and racial identity. Cultural Diversity and Ethnic Minority Psychology, 16, 237-247. doi:10.1037/a0016111

Williams, D. R., Neighbors, H. W., \& Jackson, J. S. (2003). Racial/ethnic discrimination and health: Findings from community studies. American Journal of Public Health, 93(2), 200-208. doi:10.2105/AJPH.93.2.200

Wong, C. A., Eccles, J. S., \& Sameroff, A. (2003). The influence of ethnic discrimination and ethnic identification on African American adolescents' school and socioemotional adjustment. Journal of Personality, 71, 1197-1232. doi: 10.1111/1467-6494.7106012

Wong, M. S., McElwain, N. L., \& Halberstadt, A. G. (2009). Parent, family, and child characteristics: Associations with mother-and father-reported emotion socialization practices. Journal of Family Psychology, 23, 452-463. doi: 10.1037/a0015552

Yap, M. B., Allen, N. B., \& Ladouceur, C. D. (2008). Maternal socialization of positive affect: The impact of invalidation on adolescent emotion regulation and depressive symptomatology. Child Development, 79, 1415-1431. doi:10.1111/j.14678624.2008.01196.x 
Yi, C. Y., Gentzler, A. L., Ramsey, M. A., \& Root, A. E. (2016). Linking maternal socialization of positive emotions to children's behavioral problems: The moderating role of selfcontrol. Journal of Child and Family Studies, 25, 1550-1558. doi 10.1007/s10826-0150329-x 
Table 1:

Participants' Demographic Information.

\begin{tabular}{|c|c|c|}
\hline & $\underline{\underline{N}}$ & $\underline{\underline{\%}}$ \\
\hline \multicolumn{3}{|l|}{ Parents' Gender } \\
\hline Female & 182 & 44.8 \\
\hline Male & 224 & 55.2 \\
\hline \multicolumn{3}{|l|}{ Parents' Age } \\
\hline $22-25$ years old & 24 & 5.9 \\
\hline 26-30 years old & 100 & 24.6 \\
\hline 31-35 years old & 144 & 35.5 \\
\hline $36-40$ years old & 72 & 17.7 \\
\hline 41-45 years old & 37 & 9.1 \\
\hline 46-50 years old & 16 & 3.9 \\
\hline $51-57$ years old & 10 & 2.5 \\
\hline \multicolumn{3}{|l|}{ Relationship to Child } \\
\hline Biological mother & 193 & 47.5 \\
\hline Step-mother & 3 & .7 \\
\hline Adoptive mother & 6 & 1.5 \\
\hline Biological father & 183 & 45.1 \\
\hline Step-father & 14 & 3.4 \\
\hline Adoptive father & 6 & 1.5 \\
\hline Other (e.g., custodial aunt) & 1 & .2 \\
\hline \multicolumn{3}{|l|}{ Marital Status } \\
\hline Married & 337 & 83.0 \\
\hline Single & 32 & 7.9 \\
\hline Living with partner & 223 & 5.7 \\
\hline Separated & 2 & .5 \\
\hline Divorced & 11 & 2.7 \\
\hline Widowed & 1 & .2 \\
\hline \multicolumn{3}{|l|}{ Child's Age } \\
\hline $8-9$ years old & 223 & 54.9 \\
\hline 10-11 years old & 118 & $29 . .1$ \\
\hline $12-13$ years old & 28 & 6.9 \\
\hline $14-15$ years old & 21 & 5.2 \\
\hline 16-17 years old & 13 & 3.2 \\
\hline 18 years old & 3 & .7 \\
\hline \multicolumn{3}{|l|}{ Children's Gender } \\
\hline Female & 197 & 48.5 \\
\hline Male & 209 & 51.5 \\
\hline
\end{tabular}

Education level

Did not attend school

$1 \quad .2$


$11^{\text {th }}$ grade or less

Graduated from high school

\begin{tabular}{cc}
3 & .6 \\
6 & 1.5 \\
33 & 8.1 \\
21 & 5.2 \\
195 & 48.0 \\
14 & 3.4 \\
90 & 22.2 \\
43 & 10.6 \\
\hline
\end{tabular}

Some college

2 years college degree

Graduated from 4-year college

\section{Household Income}

Less than $\$ 19,999$

11

2.7

\$20,000-39,999

46

11.3

$\$ 40,000-59,999$

93

22.9

\$60,000-79,999

$96 \quad 23.6$

$\$ 80,000-99,999$ 73

\$100,000-119,999

33

18.0

Over $\$ 120,000$

49

8.1

Prefer not to answer

5

12.1

Difficulty Paying Bills

A great deal

$69 \quad 17.0$

Some

153

37.7

A little

123

30.3

None at all

61

15.0

\section{Employment Status}

Employed working 40 or more hours a week

352

86.5

Employed working less than 40 hours a week

$41 \quad 10.1$

Not employed, looking for work

Not employed, NOT looking for work 
Table 2.

Descriptive Statistics of Main Variables.

\begin{tabular}{|c|c|c|c|c|}
\hline & $\underline{\text { Mean }(S D)}$ & $\underline{\text { Scale Range }}$ & $\underline{\text { Participants' Range }}$ & $\frac{\text { Cronbach }}{\text { Alpha }}$ \\
\hline Racial Discrimination & $3.52(1.17)$ & $1-6$ & $1-5.73$ & .92 \\
\hline \multicolumn{5}{|l|}{ Racial Socialization } \\
\hline Racial Pride & $2.33(.50)$ & $1-3$ & $1-3$ & .69 \\
\hline Racial Barrier & $2.12(.53)$ & $1-3$ & $1-3$ & .69 \\
\hline Egalitarian & $2.21(.53)$ & $1-3$ & $1-3$ & .71 \\
\hline Self-Worth & $2.34(.53)$ & $1-3$ & $1-3$ & .72 \\
\hline Negative Messages & $1.75(.62)$ & $1-3$ & $1-3$ & .84 \\
\hline Socialization Behaviors & $2.20(.46)$ & $1-3$ & $1-3$ & .69 \\
\hline \multicolumn{5}{|l|}{ Emotion Beliefs } \\
\hline Value PA & $4.60(.82)$ & $1-6$ & $2.38-6$ & .70 \\
\hline PA Dangerous & $3.86(1.17)$ & $1-6$ & $1-5.75$ & .79 \\
\hline Value NA & $4.31(.86)$ & $1-6$ & $1-6$ & .79 \\
\hline NA Dangerous & $4.06(1.03)$ & $1-6$ & $1-6$ & .78 \\
\hline \multicolumn{5}{|l|}{ PA Socialization } \\
\hline Reward PA & $3.87(.82)$ & $1-5$ & $1-5$ & .86 \\
\hline Punish PA & $2.76(1.21)$ & $1-5$ & $1-5$ & .93 \\
\hline Override PA & $2.76(1.18)$ & $1-5$ & $1-5$ & .94 \\
\hline Neglect PA & $2.59(1.24)$ & $1-5$ & $1-5$ & .95 \\
\hline Magnify PA & $3.75(.81)$ & $1-5$ & $1-5$ & .73 \\
\hline \multicolumn{5}{|l|}{ NA Socialization } \\
\hline Reward NA & $3.85(.77)$ & $1-5$ & $1-5$ & .87 \\
\hline Punish NA & $2.71(1.17)$ & $1-5$ & $1-4.89$ & .95 \\
\hline Override NA & $3.41(.69)$ & $1-5$ & $1-5$ & .74 \\
\hline Neglect NA & $2.83(1.01)$ & $1-5$ & $1-4.89$ & .93 \\
\hline Magnify NA & $2.83(1.05)$ & $1-5$ & $1-4.89$ & .91 \\
\hline
\end{tabular}

Note. $\mathrm{NA}=$ negative affect. $\mathrm{PA}=$ positive affect. 
Table 3.

Bivariate Correlations among Demographics and Main Variables.

\begin{tabular}{|c|c|c|c|c|c|c|}
\hline & $\underline{\text { Child Sex }}$ & $\underline{\text { Child Age }}$ & $\underline{\text { Parent Sex }}$ & $\underline{\text { Parent Age }}$ & $\underline{\text { Education }}$ & $\frac{\text { Difficulty }}{\text { Paying Bills }}$ \\
\hline & $\underline{r}$ & $\underline{r}$ & $\underline{r}$ & $\underline{r}$ & $\underline{r}$ & $\underline{r}$ \\
\hline Racial Discrimination & -.05 & $-.22^{* * *}$ & -.09 & $-.21^{* * * *}$ & $.21^{* * * *}$ & $-.47^{* * * *}$ \\
\hline \multicolumn{7}{|l|}{ Racial Socialization } \\
\hline Racial Pride & -.03 & $.22^{* * * *}$ & .05 & $.20 * * *$ & -.05 & .05 \\
\hline Racial Barrier & .08 & $.11^{*}$ & .01 & $.11^{*}$ & $.15^{* *}$ & $-.11^{*}$ \\
\hline Egalitarian & -.01 & $.17^{* * * *}$ & -.001 & $.19^{* * * *}$ & -.01 & .06 \\
\hline Self-Worth & -.02 & $.19^{* * * *}$ & .07 & $.18^{* * *}$ & -.05 & $.12^{*}$ \\
\hline Negative Messages & -.01 & $-.29^{* * * *}$ & $-.12^{*}$ & $-.24^{* * *}$ & $.27^{* * *}$ & $-.34^{* * * *}$ \\
\hline Socialization Behaviors & -.03 & $.10^{*}$ & .004 & $.10^{*}$ & .09 & -.06 \\
\hline \multicolumn{7}{|l|}{ Emotion Beliefs } \\
\hline Value PA & .01 & $.17^{* * * *}$ & $.14^{* *}$ & $.12^{*}$ & -.10 & -.09 \\
\hline PA Dangerous & -.004 & $-.30^{* * * *}$ & $-.11^{*}$ & $-.25^{* * *}$ & $.32^{* * *}$ & $-.29^{* * * *}$ \\
\hline Value NA & -.02 & -.04 & .04 & -.06 & .08 & $-.25^{* * *}$ \\
\hline NA Dangerous & -.02 & $-.21^{* * * *}$ & -.09 & $-.20^{* *}$ & $.26^{* * *}$ & $-.23^{* * *}$ \\
\hline \multicolumn{7}{|l|}{ PA Socialization } \\
\hline Reward PA & -.01 & $.19^{* * * *}$ & $.10^{*}$ & $.15^{* * *}$ & -.06 & .04 \\
\hline Punish PA & -.05 & $-.32^{* * *}$ & $-.11^{*}$ & $-.27^{* * *}$ & $.31^{* * *}$ & $-.40^{* * *}$ \\
\hline Override PA & -.05 & $-.35^{* * * *}$ & $-.13^{* * *}$ & $-.29^{* * * *}$ & $.31^{* * *}$ & $-.42^{* * * *}$ \\
\hline Neglect PA & $-.10 *$ & $-.30^{* * * *}$ & $-.15^{* *}$ & $-.23^{* * *}$ & $.27^{* * *}$ & $-.42^{* *}$ \\
\hline Magnify PA & -.01 & .04 & $.11^{*}$ & .02 & -.01 & -.08 \\
\hline \multicolumn{7}{|l|}{ NA Socialization } \\
\hline$\overline{\text { Reward NA }}$ & -.03 & $.14^{* *}$ & .07 & $.12^{*}$ & -.07 & .06 \\
\hline Punish NA & -.07 & $-.33^{* * *}$ & $-.13^{*}$ & $-.27^{* * * *}$ & $.30^{* * * *}$ & $-.43^{* * *}$ \\
\hline Override NA & $-.12^{*}$ & $-.15^{* *}$ & -.05 & -.09 & $.18^{* * *}$ & $-.25^{* * *}$ \\
\hline Neglect NA & -.08 & $-.28^{* * * *}$ & $-.13^{* * *}$ & $-.24^{* * *}$ & $.28^{* * *}$ & $-.46^{* * * *}$ \\
\hline Magnify NA & -.06 & $-.27^{* * *}$ & -.06 & $-.24^{* * *}$ & $.27^{* * *}$ & $-.47^{* * *}$ \\
\hline
\end{tabular}

Note. ${ }^{*} p<.05,{ }^{* *} p<.01,{ }^{* * *} p<.001$. Sex coded $1=$ male, $2=$ female. $\mathrm{NA}=$ negative affect.

$\mathrm{PA}=$ positive affect. 
Table 4.

Bivariate Correlations among Covariates and Control Variables.

\begin{tabular}{|c|c|c|c|c|c|c|}
\hline & $\begin{array}{l}\frac{\text { Child's }}{\text { Exp.w/ }} \\
\frac{\text { Discrim. }}{r}\end{array}$ & $\frac{\frac{\text { Vicarious }}{\text { Discrim. }}}{\underline{r}}$ & $\frac{\underline{\text { Life }}}{\underline{\text { Satisfaction }}}$ & $\frac{\frac{\text { Anger }}{\text { Expression }}}{\underline{r}}$ & $\underline{\text { Depression }}$ & $\frac{\% \text { of AA }}{\text { Per County }}$ \\
\hline $\begin{array}{l}\text { Racial } \\
\text { Discrimination }\end{array}$ & $.72^{* * * *}$ & $.54^{* * *}$ & $.34^{* * *}$ & $.70^{* * *}$ & $.69^{* * * *}$ & $-.11^{*}$ \\
\hline \multicolumn{7}{|l|}{ Racial Socialization } \\
\hline Racial Pride & -.06 & $.21^{* * * *}$ & .06 & $-.16 * *$ & $-.23^{* * * *}$ & $.16^{* *}$ \\
\hline Racial Barrier & $.25^{* * *}$ & $.41^{* * * *}$ & $.10^{*}$ & $.18^{* * *}$ & $.15^{* *}$ & $.11^{*}$ \\
\hline Egalitarian & -.00 & $.19^{* * *}$ & $.13^{*}$ & $-.11^{*}$ & $-.18^{* * * *}$ & $.18^{* * * *}$ \\
\hline Self-Worth & $.15^{* *}$ & $.11^{*}$ & -.00 & $-.25^{* * * *}$ &.$- .33^{* * * *}$ & $.17^{* * * *}$ \\
\hline Negative Messages & $.58^{* * *}$ & $.34^{* * *}$ & $.40^{* * * *}$ & $.68^{* * *}$ & $.68^{* * *}$ & -.07 \\
\hline Soc. Behaviors & $.14^{* *}$ & $.3^{* * *}$ & $.14^{*}$ & .06 & .01 & $.17^{* * *}$ \\
\hline \multicolumn{7}{|l|}{ Emotion Beliefs } \\
\hline Value PA & .04 & $.35^{* * *}$ & $.20^{* * *}$ & -.01 & $-.13^{* *}$ & $.17^{* * *}$ \\
\hline PA Dangerous & $.56^{* *}$ & $.39^{* * *}$ & $.45^{* * *}$ & $.70^{* * * *}$ & $.67^{* * *}$ & -.09 \\
\hline Value NA & $.32^{* *}$ & $.49^{* * *}$ & $.26^{* * * *}$ & $.39^{* * * *}$ & $.31^{* * * *}$ & -.01 \\
\hline NA Dangerous &. $\mathbf{4 6} * * *$ & $.41^{* * * *}$ & $.40^{* * * *}$ & $.56^{* * *}$ & $.50^{* * * *}$ & .01 \\
\hline \multicolumn{7}{|l|}{ PA Socialization } \\
\hline Reward PA & -.08 & $.25^{* * *}$ & .08 & $-.13 * *$ & $-.25^{* * *}$ & $.20^{* * *}$ \\
\hline Punish PA & $.64^{* * * *}$ & $.38^{* * *}$ & $.46^{* * *}$ & $.79^{* * *}$ & $.77^{* * * *}$ & $-.11^{*}$ \\
\hline Override PA & $.64^{* * * *}$ & $.37^{* * *}$ & $.47^{* * *}$ & $.79^{* * * *}$ & $.78^{* * *}$ & $-.11^{*}$ \\
\hline Neglect PA & $-.66^{* * *}$ & $-.37^{* * *}$ & $.39^{* * * *}$ & $.76^{* * *}$ & $.78^{* * *}$ & -.10 \\
\hline Magnify PA & .05 & $.28^{* * *}$ & $.15^{* *}$ & -.02 & $-.10 *$ & $-.17^{* *}$ \\
\hline \multicolumn{7}{|l|}{ NA Socialization } \\
\hline Reward NA & -.04 & $.28^{* * * *}$ & $.13^{* *}$ & -.01 & $-.24^{* * *}$ & $.18^{* * * *}$ \\
\hline Punish NA & $.70^{* * * *}$ & $.39^{* * * *}$ & $.41^{* * * *}$ & $.82^{* * *}$ & $.81^{* * *}$ & $-.13^{*}$ \\
\hline Override NA & $.41^{* * *}$ & $.39^{* * *}$ & $.33^{* * * *}$ & $.47^{* * *}$ & $.40^{* * *}$ & .05 \\
\hline Neglect NA & $.71^{* * * *}$ & $.41^{* * *}$ & $.41^{* * * *}$ & $.79^{* * *}$ & $.80^{* * * *}$ & -.10 \\
\hline Magnify NA & $.71^{* * *}$ & $.45^{* * *}$ & $.38^{* * *}$ & $.79^{* * *}$ & $.81^{* * * *}$ & -.08 \\
\hline
\end{tabular}

Note. ${ }^{*} p<.05,{ }^{* *} p<.01 .{ }^{* * *} p<.001$. Exp $=$ experience. Discrim $=$ discrimination. NA = negative affect. $\mathrm{PA}=$ positive affect. Soc. $=$ socialization. AA= African American . 
Table 5.

Bivariate Correlations Among Main Variables of Interest.

\begin{tabular}{|c|c|c|c|c|c|c|c|c|c|c|c|c|c|c|c|c|c|c|c|c|}
\hline & 1 & 2 & 3 & 4 & 5 & 6 & 7 & 8 & 9 & 10 & 11 & 12 & 13 & 14 & 15 & 16 & 17 & 18 & 19 & 20 \\
\hline 1. Discrim. & - & & & & & & & & & & & & & & & & & & & \\
\hline Racial Soc. & & & & & & & & & & & & & & & & & & & & \\
\hline $\begin{array}{l}\text { 2. Racial } \\
\text { Pride }\end{array}$ & $-.10^{*}$ & & & & & & & & & & & & & & & & & & & \\
\hline $\begin{array}{l}\text { 3. Racial } \\
\text { Barrier }\end{array}$ & $.28^{* * *}$ & $.49^{* * *}$ & - & & & & & & & & & & & & & & & & & \\
\hline 4.Egalitarian & -.07 & $.58^{* * *}$ & $.36^{* * *}$ & - & & & & & & & & & & & & & & & & \\
\hline 5. Self W. & $-.19^{* * *}$ & $.63^{* * *}$ & $.34^{* * *}$ & $.57^{* * * *}$ & - & & & & & & & & & & & & & & & \\
\hline 6. Negative & $.61^{* * *}$ & $-.16^{* *}$ & $.24^{* * *}$ & -.07 & $-.21^{* * * *}$ & - & & & & & & & & & & & & & & \\
\hline $\begin{array}{l}\text { 7. Behavior } \\
\text { Emotion } \\
\underline{\text { Beliefs }}\end{array}$ & $.13^{* *}$ & $.57^{* * * *}$ & $.47^{* * * *}$ & $.47^{* * * *}$ & $.49^{* * * *}$ & $.11^{*}$ & - & - & & & & & & & & & & & & \\
\hline 8. Value PA & .03 & $.45^{* * *}$ & $.18^{* * *}$ & $.35^{* * *}$ & $.40^{* * *}$ & $-.16^{* *}$ & $.34^{* * * *}$ & & & & & & & & & & & & & \\
\hline $\begin{array}{l}\text { 9. PA } \\
\text { Danger }\end{array}$ & $.62^{* * * *}$ & $-.25^{* * *}$ & $.16^{* *}$ & -.09 & $-.27^{* * *}$ & $.68^{* * *}$ & -.06 & $-.12^{*}$ & - & & & & & & & & & & & \\
\hline $\begin{array}{l}\text { 10. Value } \\
\text { NA }\end{array}$ & $.40^{* * * *}$ & $.19^{* * * *}$ & $.23^{* * * *}$ & $.18^{*}$ & .09 & $.24^{* * * *}$ & $.29^{* * * *}$ & $.50^{* * *}$ & $.31^{* * *}$ & - & & & & & & & & & & \\
\hline $\begin{array}{l}\text { 11. NA } \\
\text { Danger }\end{array}$ & $.49^{* * * *}$ & $-.10^{*}$ & $.24^{* * * *}$ & .01 & $-.11^{*}$ & $.52^{* * * *}$ & .05 & $.12^{*}$ & $.67^{* * *}$ & $.16^{* * * *}$ & - & & & & & & & & & \\
\hline PA Soc. & & & & & & & & & & & & & & & & & & & & \\
\hline 12. Reward & -.07 & $.49^{* * * *}$ & $.20^{* * * *}$ & $.41^{* * * *}$ & $.52^{* * * *}$ & $-.28^{* * *}$ & $.35^{* * *}$ & $.67^{* * * *}$ & $-.17^{* * *}$ & $.33^{* * *}$ & -.01 & - & & & & & & & & \\
\hline 13. Punish & $.69^{* * *}$ & $-.23^{* * *}$ & $.15^{* *}$ & $-.15^{* *}$ & $-.38^{* * *}$ & $.77^{* * * *}$ & -.01 & $-.15^{* *}$ & $.81^{* * *}$ & $.28^{* *}$ & $.59^{* * *}$ & $-.21^{* * *}$ & - & & & & & & & \\
\hline 14. Override & $.72^{* * * *}$ & $-.27^{* * *}$ & $.17^{* * *}$ & $-.16^{* *}$ & $-.38^{* * * *}$ & $.80^{* * *}$ & -.01 & $-.14^{* *}$ & $.80^{* * * *}$ & $.27^{* * * *}$ & $.60^{* * *}$ & $-.22^{* * *}$ & $.92^{* * *}$ & - & & & & & & \\
\hline 15. Neglect & $.71^{* * *}$ & $-.28^{* * *}$ & $.14^{* *}$ & $-.16^{* *}$ & $-.36^{* * *}$ & $.73^{* * *}$ & -.01 & $-.16^{* *}$ & $.72^{* * * *}$ & $.27^{* * * *}$ & $.52^{* * *}$ & $-.27^{* * *}$ & $.86^{* * * *}$ & $.87^{* * * *}$ & - & & & & & \\
\hline 16. Magnify & .08 & $.42^{* * *}$ & $.20^{* * * *}$ & $.35^{* * *}$ & $.42^{* * *}$ & -.08 & $.38^{* * * *}$ & $.64^{* *}$ & -.04 & $.33^{* * *}$ & $.11^{*}$ & $.77^{* * * *}$ & -.05 & -.04 & $-.12^{* *}$ & - & & & & \\
\hline NA Soc. & & & & & & & & & & & & & & & & & & & & \\
\hline 17. Reward & -.02 & $.50^{* * *}$ & $.21^{* * *}$ & $.45^{* *}$ & $.54^{* * *}$ & $-.22^{* * *}$ & $.41^{* * * *}$ & $.68^{* *}$ & $-.13^{*}$ & $.35^{* * * *}$ & .09 & $.81^{* * * *}$ & $-.18^{* * *}$ & $-.19^{* * *}$ & $-.23^{* * *}$ & $.73^{* * * *}$ & - & & & \\
\hline 18. Punish & $.75^{* * *}$ & $-.27^{* * *}$ & $.18^{* * * *}$ & $-.19^{* * *}$ & $-.36^{* * *}$ & $.77^{* * * *}$ & -.02 & $-.16^{* *}$ & $.78^{* * *}$ & $.31^{* * * *}$ & $.58^{* * *}$ & $-.26^{* * *}$ & $.90^{* * * *}$ & $.91^{* * * *}$ & $.91^{* * *}$ & -.08 & $-.21^{* * *}$ & - & & \\
\hline 19. Override & $.45^{* * * *}$ & $.21^{* * *}$ & $.29^{* * * *}$ & $.26^{* * * *}$ & $.18^{* * *}$ & $.36^{* * *}$ & $.31^{* * * *}$ & $.32^{* * *}$ & $.42^{* * *}$ & $.28^{* * * *}$ & $.58^{* * * *}$ & $.42^{* * * *}$ & $.46^{* * *}$ & $.46^{* * *}$ & $.40^{* * * *}$ & $.50^{* * * *}$ & $.51^{* * * *}$ & $.45^{* * * *}$ & - & \\
\hline 20. Neglect & $.76^{* * * *}$ & $-.21^{* * *}$ & $.18^{* * *}$ & $-.18^{* *}$ & $-.29^{* * * *}$ & $.72^{* * *}$ & -.02 & -.06 & $.74^{* *}$ & $.38^{* * * *}$ & $.57^{* * *}$ & $-.16^{* *}$ & $.86^{* * *}$ & $.86^{* * * *}$ & $.89^{* * *}$ & -.01 & $-.10^{*}$ & $.92^{* * * *}$ & $.51^{* * *}$ & - \\
\hline 21. Magnify & $.74^{* * * *}$ & $-.18^{* * * *}$ & $.21^{* * *}$ & $-.14^{* *}$ & $-.30^{* * *}$ & $.70^{* * * *}$ & .04 & -.05 & $.71^{* * *}$ & $.36^{* * *}$ & $.55^{* * *}$ & $-.16^{* *}$ & $.84^{* * *}$ & $.83^{* * *}$ & $.86^{* * *}$ & .01 & $-.12^{*}$ & $.91^{* * * *}$ & $.50^{* * *}$ & $.88^{* * *}$ \\
\hline
\end{tabular}


Table 6.

Bivariate Correlations among Racial Discrimination, Emotional Beliefs, and Emotion Socialization.

\section{Racial Discrimination}

$r$

\section{Positive Emotional Beliefs}

Value Happiness $\quad-.09$

Value Pride

$.14^{* * *}$

Happiness Dangerous/Costly $\quad \mathbf{. 6 1}^{* * * *}$

Pride Dangerous/Costly

$.51^{* * * *}$

\section{Negative Emotional Beliefs}

Value Anger

$.33^{* * *}$

Value Sadness

$.32^{* * * *}$

Value Fear

$.40^{* * * *}$

Anger Dangerous/Costly

$.35^{\text {**** }}$

Sadness Dangerous/Costly

$.51^{* * * *}$

Fear Dangerous/Costly

$.48^{* * * *}$

\section{PA Socialization}

Reward Happiness

$-.09$

Reward Pride

Override Happiness

$-.05$

Override Pride

$.69^{* * * *}$

Magnify Happiness

$.71^{* * * *}$

Magnify Pride

.04

Punish Happiness

Punish Pride

.09

Neglect Happiness

$.66^{* * *}$

Neglect Pride

$.68^{* * *}$

$.69^{* * *}$

\section{NA Socialization}

Reward Sadness

$.69^{* * *}$

Reward Anger

$-.13^{* *}$

Reward Fear

.05

Override Sadness

Override Anger

Override Fear

Magnify Sadness

Magnify Anger

Magnify Fear

Punish Sadness

Punish Anger

Punish Fear

.02

.30 **

$.51^{* * * *}$

$.28^{* * *}$

$.67^{* * *}$

$.70^{\text {**** }}$

$.68^{* * * *}$

$.72^{* * * *}$

$.70^{* * * *}$

$.73^{* * * *}$

Neglect Sadness

$.70^{* * * *}$

Neglect Anger

$.72^{* * * *}$

Neglect Fear

$.71^{* * * *}$

Note. ${ }^{*} p<.05,{ }^{* *} p<.01 .{ }^{* * *} p<.001 . \mathrm{NA}=$ negative affect. $\mathrm{PA}=$ positive affect. 
Table 7

Unstandardized Estimates and Standard Errors of Structural Model Testing Associations among Covariates, Racial Discrimination, PA Beliefs, and PA Socialization.

\begin{tabular}{|c|c|c|c|c|c|c|c|c|c|c|}
\hline & \multicolumn{2}{|c|}{ Value PA } & \multicolumn{2}{|c|}{$\frac{\text { PA Dangerous/ }}{\text { Costly }}$} & $\begin{array}{r}\text { Suppo } \\
\text { PA } \\
\text { Socializ }\end{array}$ & & $\begin{array}{r}\text { Unsup } \\
\underline{P} \\
\text { Social }\end{array}$ & $\begin{array}{l}\text { tive } \\
\text { tion }\end{array}$ & \multicolumn{2}{|c|}{$\begin{array}{c}\underline{\text { Racial }} \\
\underline{\text { Socialization }}\end{array}$} \\
\hline & $\underline{B}$ & $\underline{S E}$ & $\underline{B}$ & $\underline{S E}$ & $\underline{B}$ & $\underline{S E}$ & $\underline{B}$ & $\underline{S E}$ & $\underline{B}$ & $\underline{S E}$ \\
\hline \multicolumn{11}{|l|}{ Covariates } \\
\hline Parent Age & $.02^{* *}$ & .01 & $-.02^{* *}$ & .01 & .003 & .01 & -.01 & .004 & $.01^{* *}$ & .003 \\
\hline Parent Sex & $.24^{* *}$ & .08 & -.16 & .09 & .02 & .06 & -.08 & .06 & -.02 & .04 \\
\hline Education & -.04 & .03 & $.14^{* * * *}$ & .03 & .02 & .02 & $.04^{*}$ & .02 & $.02 *$ & .01 \\
\hline Difficulty Paying Bills & -.06 & .05 & -.03 & .05 & .03 & .03 & $-.15^{* * *}$ & .03 & .02 & .02 \\
\hline$\underline{\text { Racial Discrimination }}$ & .04 & .04 & $.53^{* * *}$ & .04 & .01 & .03 & $.31^{* * *}$ & .03 & .02 & .02 \\
\hline Value PA & -- & -- & -- & -- & $.68^{* * * *}$ & .04 & $-.14^{* * * *}$ & .04 & $.23^{* * * *}$ & .02 \\
\hline PA Costly/Dangerous & -- & -- & -- & -- & -.03 & .03 & $.54^{* * * *}$ & .03 & $-.07^{\text {**** }}$ & .02 \\
\hline
\end{tabular}

Note. $\mathrm{PA}=$ Positive Affect. ${ }^{*} p<.05,{ }^{* *} p<.01,{ }^{* * *} p<.001$. 
Table 8.

Unstandardized Estimates and Standard Errors of Structural Model Testing Associations among Covariates, Racial Discrimination, NA Beliefs, and NA Socialization.

\begin{tabular}{|c|c|c|c|c|c|c|c|c|c|c|}
\hline & \multirow{3}{*}{\multicolumn{2}{|c|}{$\underline{\text { Value NA }}$}} & \multirow{2}{*}{\multicolumn{2}{|c|}{ NA Dangerous/ }} & \multicolumn{2}{|c|}{ Supportive } & \multicolumn{2}{|c|}{ Unsupportive } & \\
\hline & & & & & \multirow{2}{*}{\multicolumn{2}{|c|}{$\stackrel{\text { NA }}{\text { Socialization }}$}} & \multirow{2}{*}{\multicolumn{2}{|c|}{$\frac{\text { NA }}{\text { Socialization }}$}} & & \\
\hline & & & & & & & & & \multicolumn{2}{|c|}{ Socialization } \\
\hline & $\underline{B}$ & $\underline{S E}$ & $\underline{B}$ & $\underline{S E}$ & $\underline{B}$ & $\underline{S E}$ & $\underline{B}$ & $\underline{S E}$ & $\underline{B}$ & $\underline{S E}$ \\
\hline \multicolumn{11}{|l|}{ Covariates } \\
\hline Parent Age & .004 & .01 & $-.01^{*}$ & .01 & .00 & .00 & $-.01^{*}$ & .004 & $.01^{* *}$ & .003 \\
\hline Parent Sex & .13 & .08 & -.11 & .09 & -.01 & .01 & $-.11^{*}$ & .05 & -.003 & .03 \\
\hline Education & .01 & .03 & $.10^{* * * *}$ & .03 & .01 & .01 & $.06^{* * *}$ & .02 & .01 & .01 \\
\hline Difficulty Paying Bills & -.10 & .05 & -.03 & .05 & -.01 & .01 & $-.14^{* * *}$ & .03 & -.01 & .02 \\
\hline$\underline{\text { Racial Discrimination }}$ & $.28^{* * * *}$ & .04 & $.36^{* * * *}$ & .04 & .02 & .01 & $.43^{* * *}$ & .03 & -.02 & .02 \\
\hline Value NA & -- & -- & -- & -- & -.01 & .01 & $.11^{* *}$ & .03 & .01 & .02 \\
\hline NA Costly/Dangerous & -- & -- & -- & -- & .04 & .02 & $.25^{* * *}$ & .03 & -.03 & .02 \\
\hline
\end{tabular}

Note. NA = Negative Affect. ${ }^{*} p<.05,{ }^{* *} p<.01,{ }^{* * *} p<.001$. 


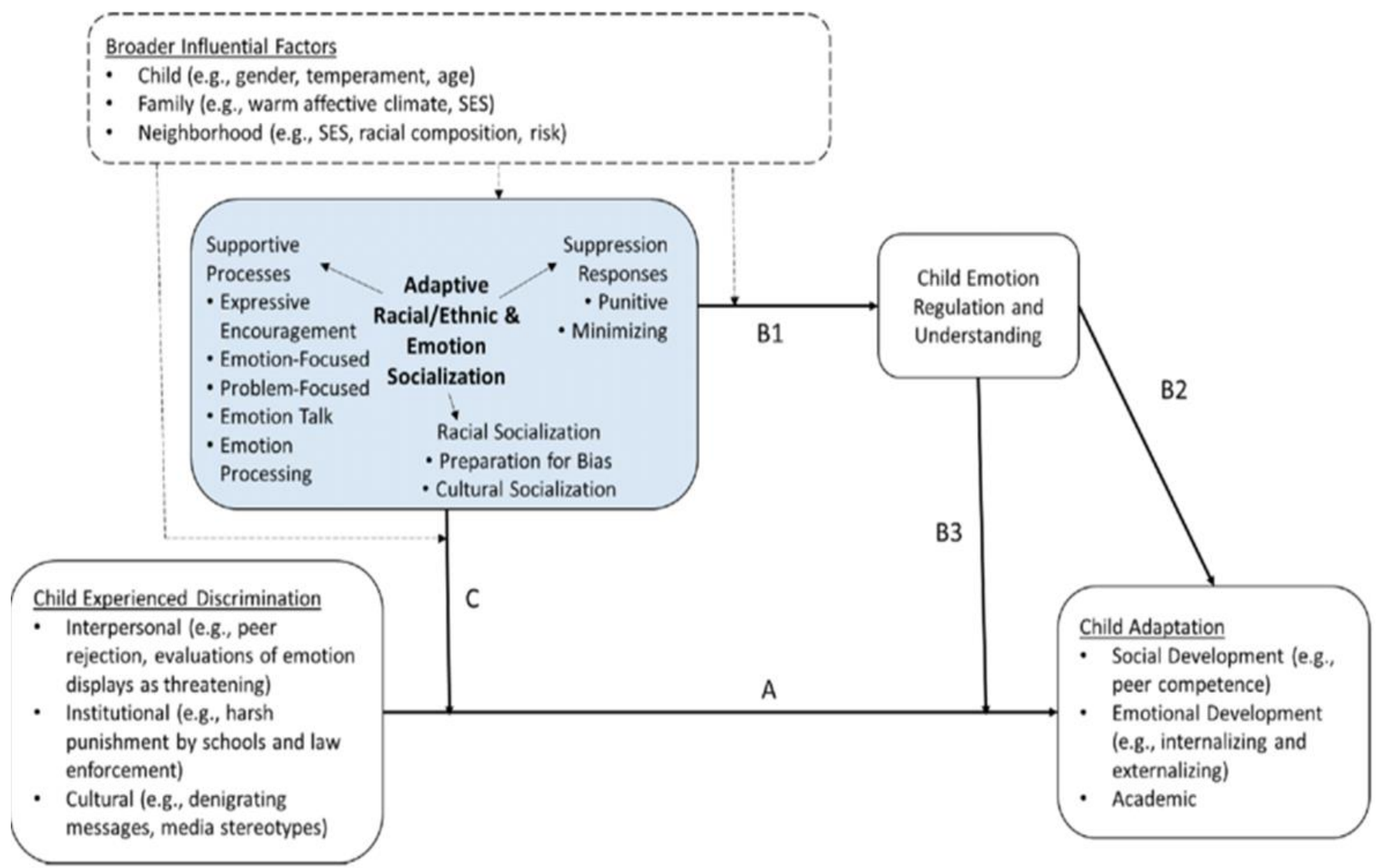

Figure 1. Dunbar and colleagues (2017) combined model of racial/ethnic and emotion socialization. 


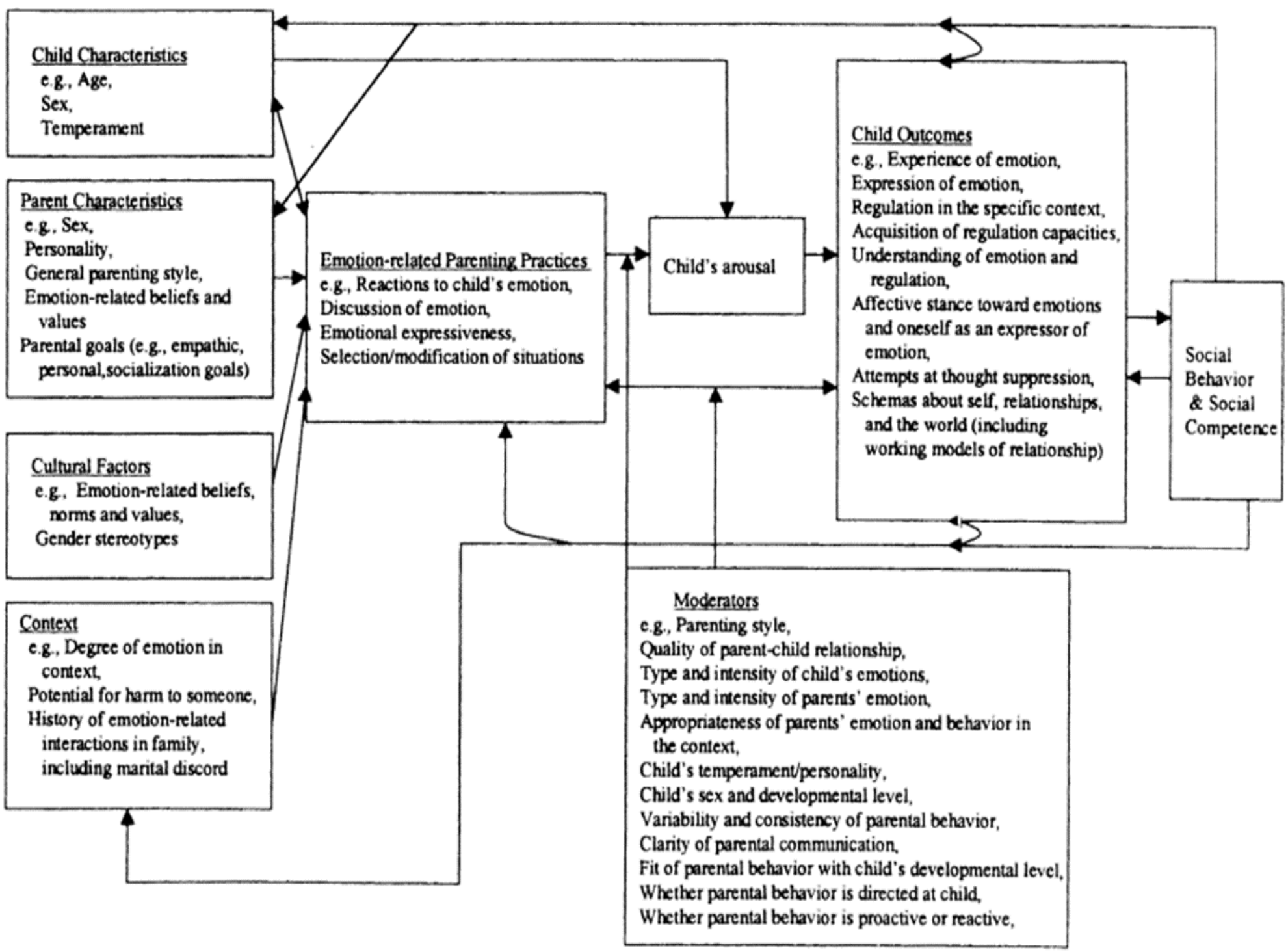

Figure 2. Eisenberg, Spinrad, and Cumberland's heuristic model of emotion socialization. 


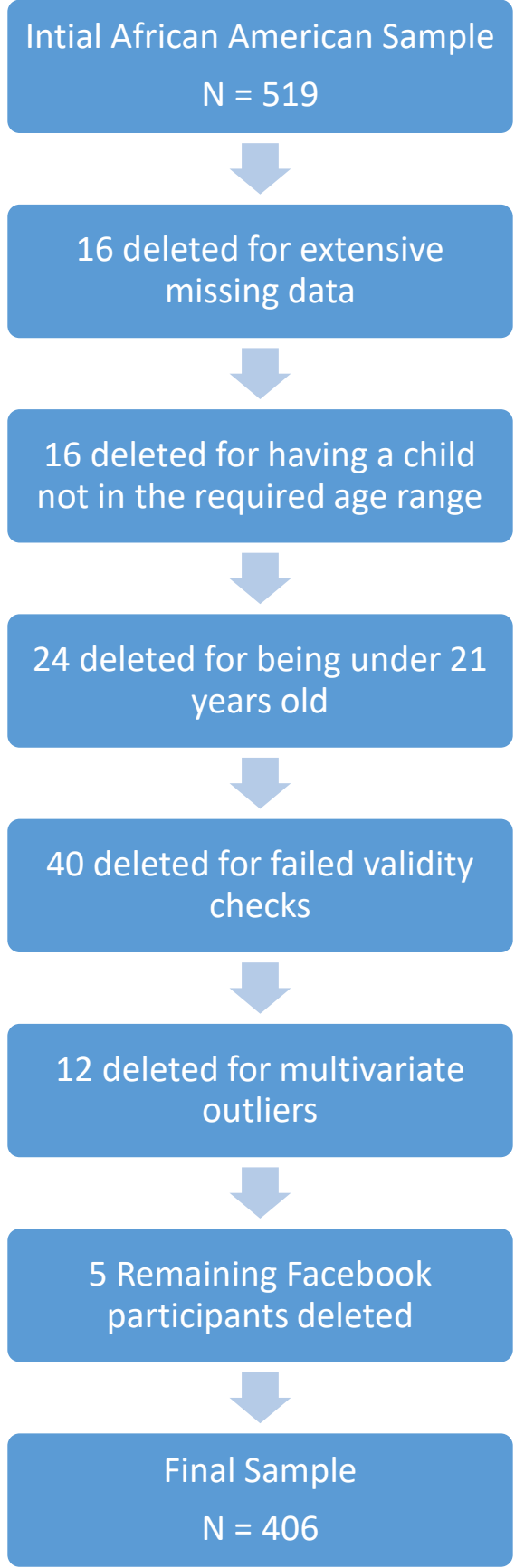

Figure 3. Participant deletion. 


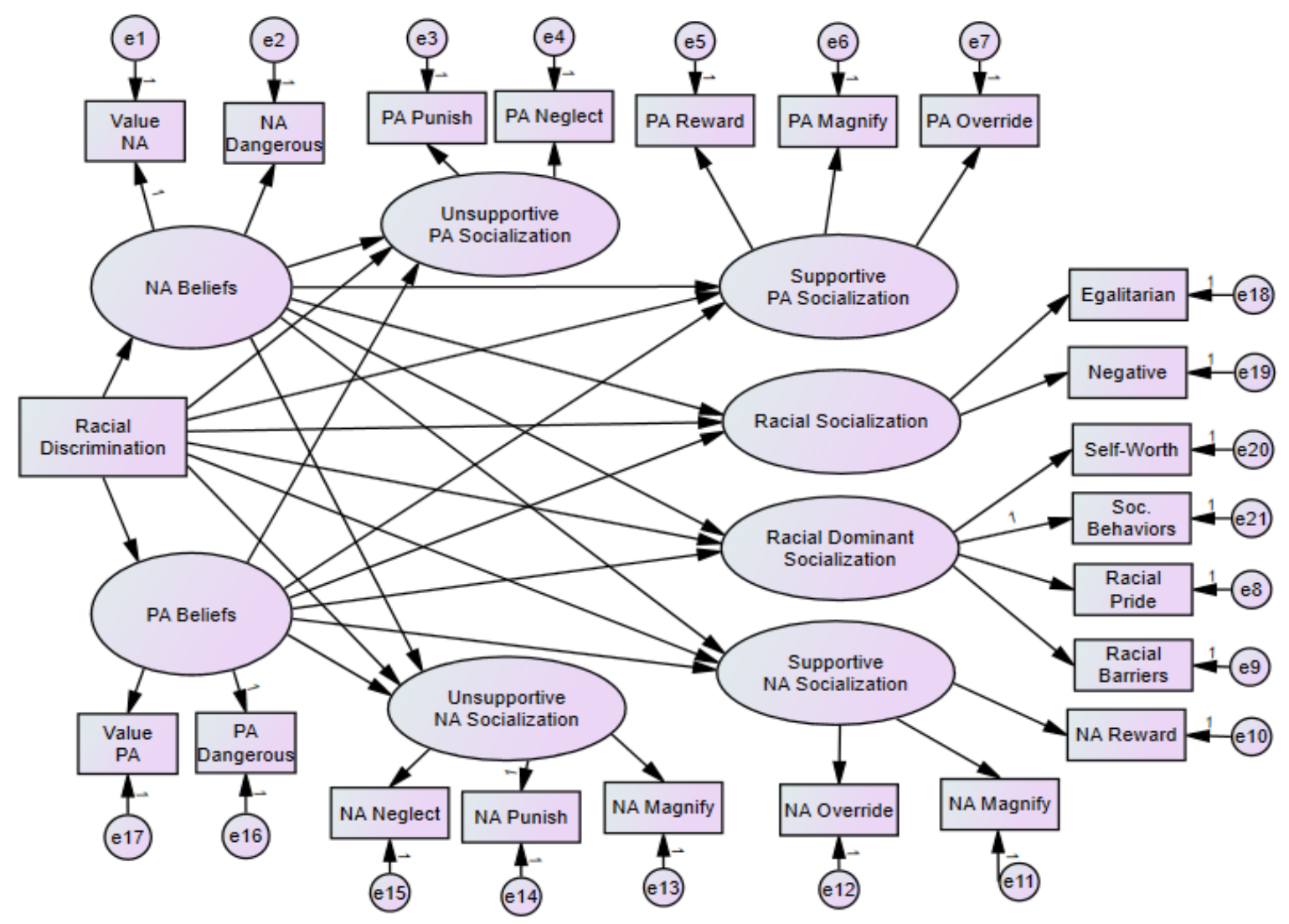

Figure 4. Proposed model using structural equation modeling. 


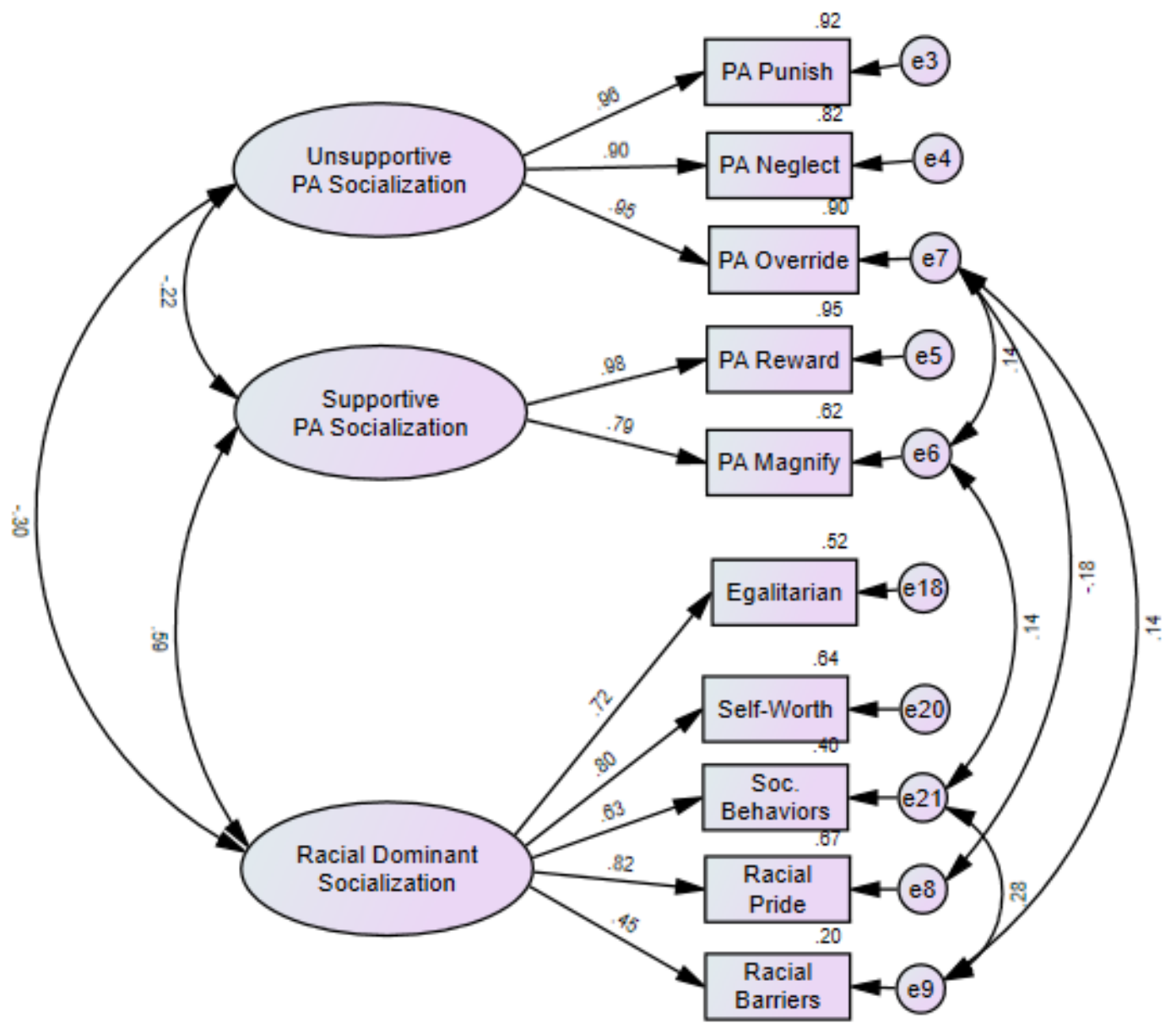

Figure 5. Positive Emotions Measurement Model. 


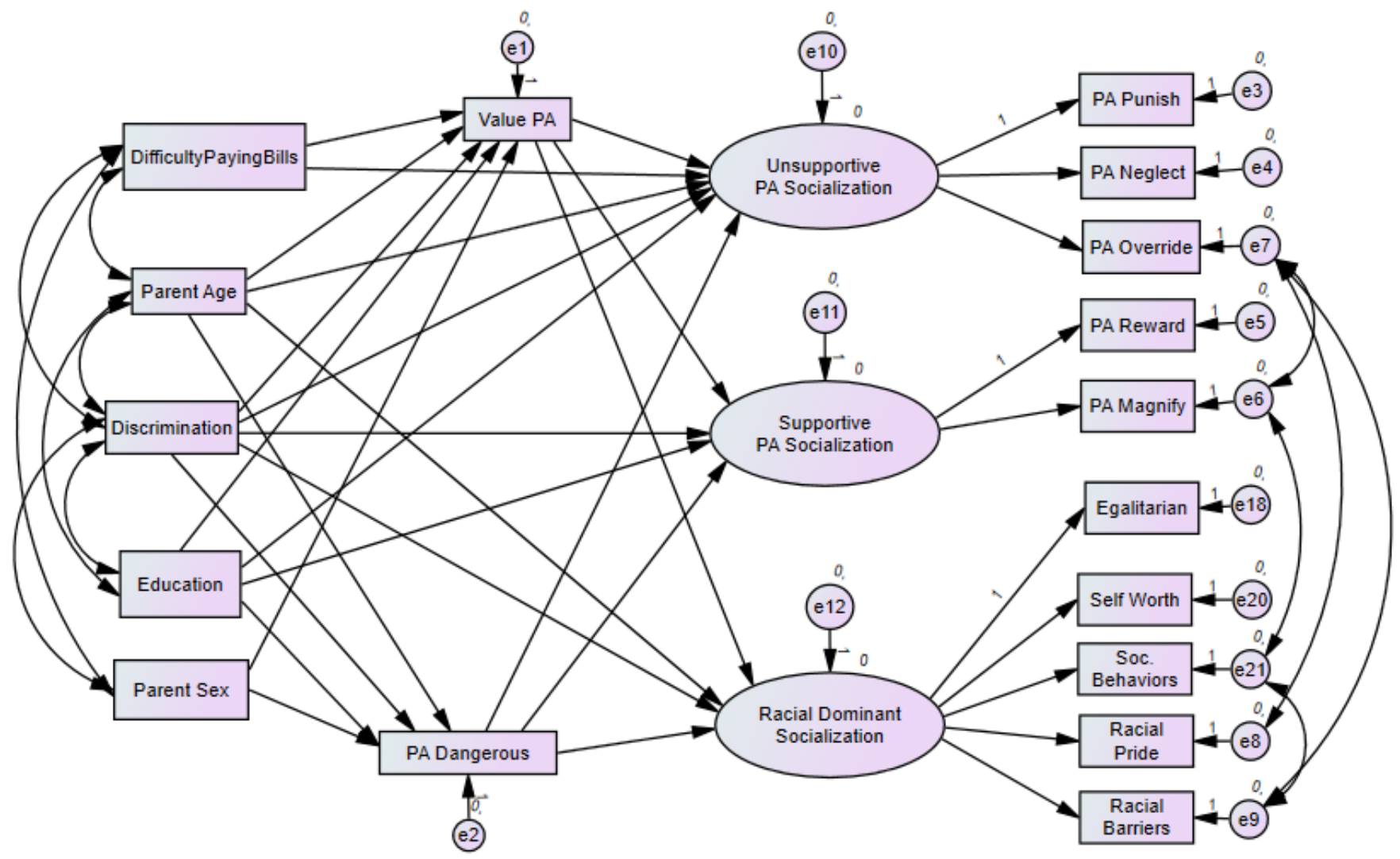

Figure 6. Positive Emotions Structural Model. 


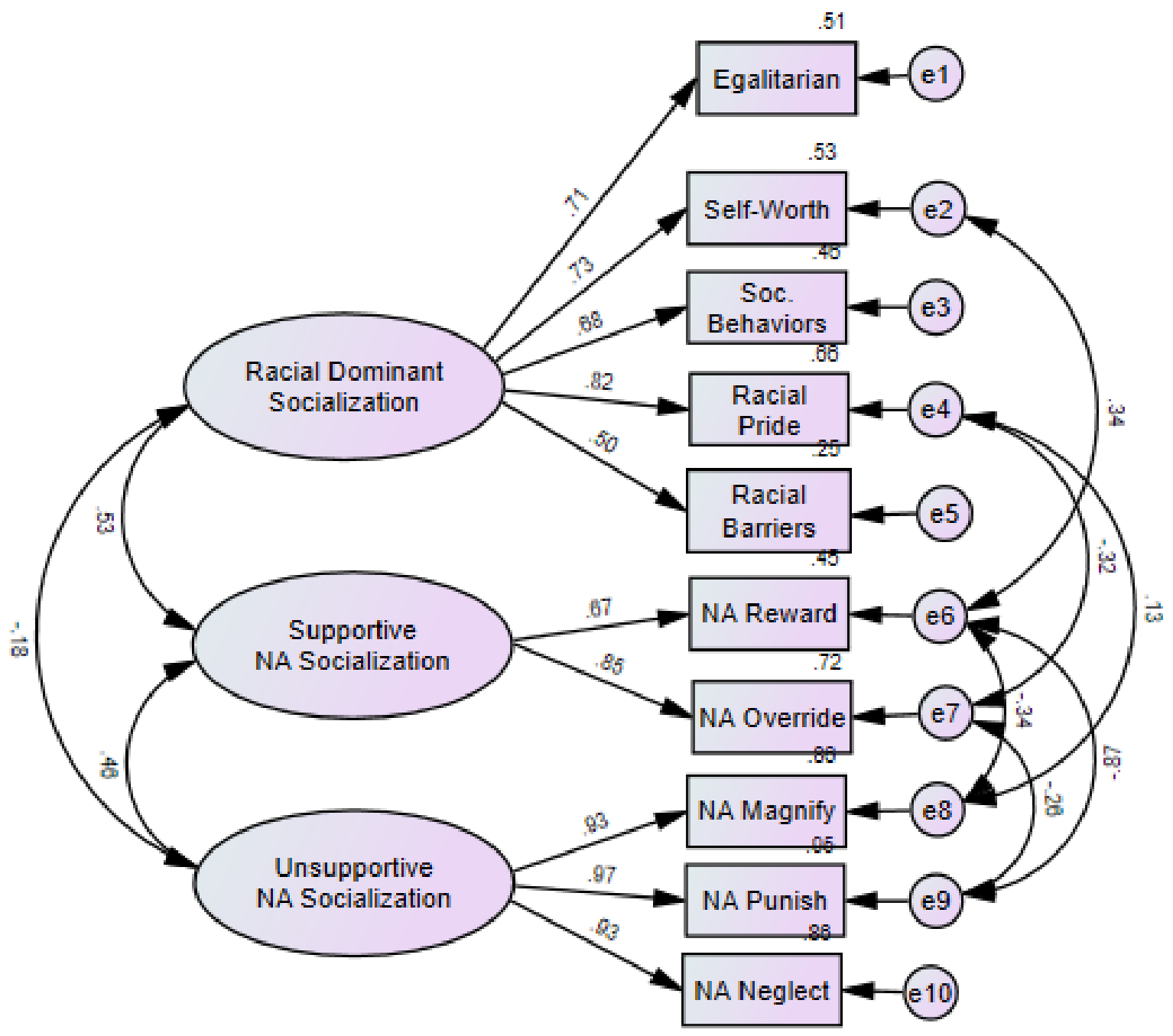

Figure 7. Negative Emotions Measurement Model. 


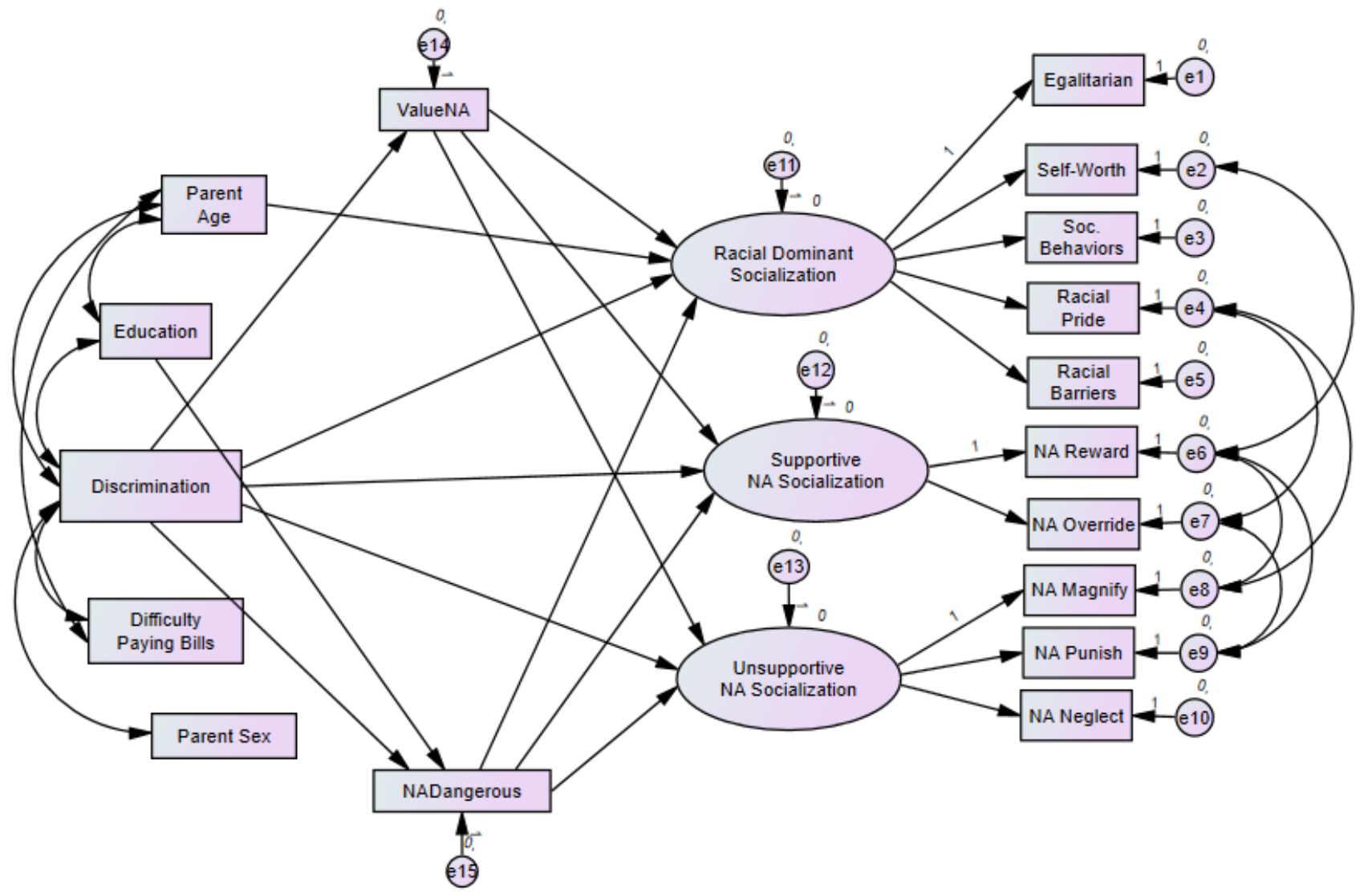

Figure 8. Negative Emotions Structural Model. 


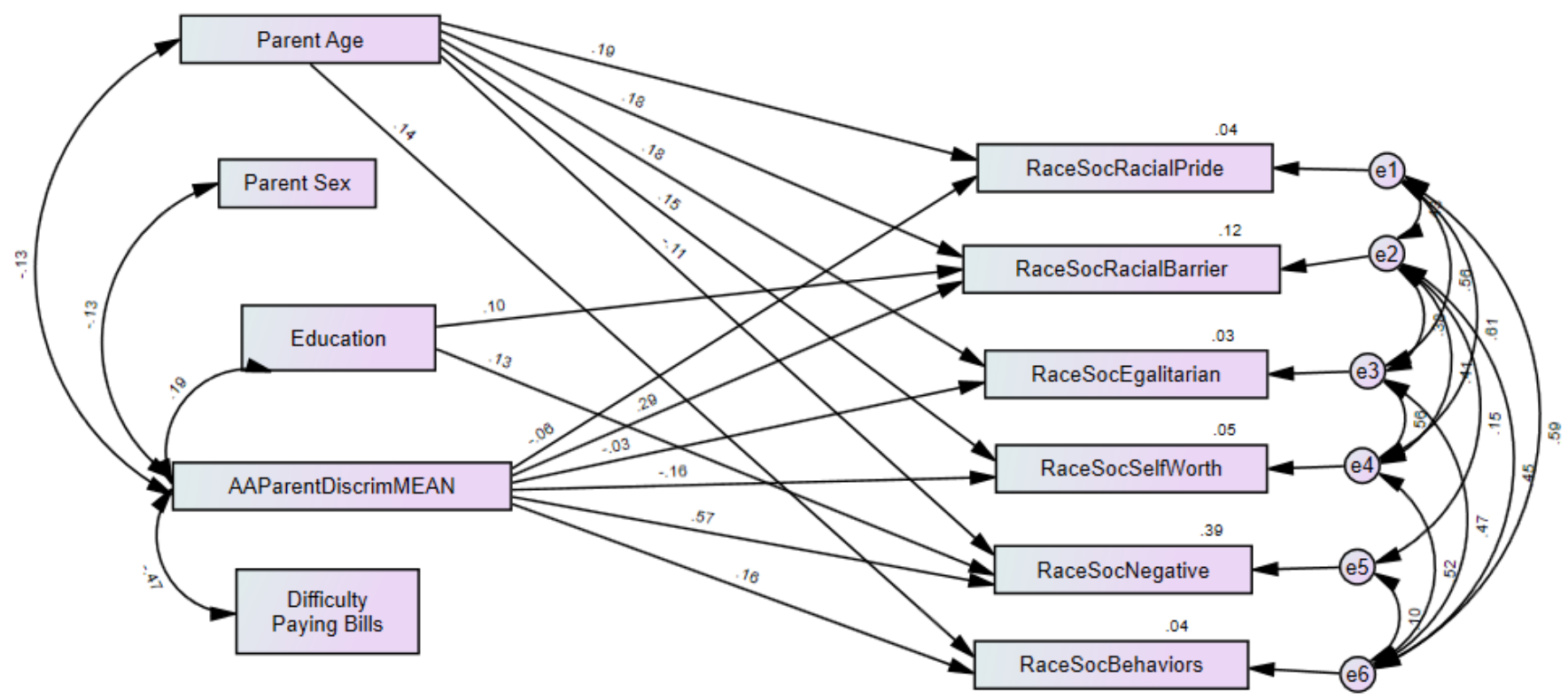

Figure 9. Racial Discrimination Predicting Racial Socialization Behaviors Structural Model. 
Appendices 


\section{Appendix A}

We are interested in your experiences with racism. As you answer the questions below, please think about your ENTIRE LIFE, from when you were a child to the present. For each question, please circle the number that best captures the things that have happened to you. Answer each question TWICE, once for what has happened to you IN THE PAST YEAR, and once for what YOUR ENTIRE LIFE HAS BEEN LIKE. Use these numbers:

Circle 1 = If this has NEVER happened to you

Circle 2 = If this has happened ONCE IN A WHILE (less than $10 \%$ of the time)

Circle $3=$ If this has happened SOMETIMES $(10 \%-25 \%$ of the time)

Circle $4=$ If this has happened A LOT $(26 \%-49 \%$ of the time)

Circle $5=$ If this has bappened MOST OF THE TIME $(50 \%-70 \%$ of the time)

Circle $6=$ If this has happened ALMOST ALL OF THE TIME (more than $70 \%$ of the time)

1. How many times have you been treated unfairly by teachers and professors because you are Black?

\begin{tabular}{|c|c|c|c|c|c|c|}
\hline How many times in the past year? & 1 & 2 & 3 & 4 & 5 & 6 \\
\hline How many times in your entire life? & 1 & 2 & 3 & 4 & 5 & \\
\hline & \multicolumn{5}{|c|}{ Not at All } & Extremely \\
\hline How stressful was this for you? & 1 & 2 & 3 & 4 & 5 & 6 \\
\hline
\end{tabular}

2. How many times have you been treated unfairly by your employers, bosses and supervisors because you are Black?

$\begin{array}{lllllll}\text { How many times in the past year? } & 1 & 2 & 3 & 4 & 5 & 6 \\ \text { How many times in your entire life? } & 1 & 2 & 3 & 4 & 5 & 6 \\ & \text { Not at All } & & & & \text { Extremely } \\ \text { How stressful was this for you? } & 1 & 2 & 3 & 4 & 5 & 6\end{array}$


3. How many times have you been treated unfairly by your coworkers, fellow students and colleagues because you are Black?

$\begin{array}{lllllll}\text { How many times in the past year? } & 1 & 2 & 3 & 4 & 5 & 6\end{array}$

$\begin{array}{llllllll}\text { How many times in your entire life? } & 1 & 2 & 3 & 4 & 5 & 6\end{array}$ Not at All Extremely

$\begin{array}{llllllll}\text { How stressful was this for you? } & 1 & 2 & 3 & 4 & 5 & 6\end{array}$

4. How many times have you been treated unfairly by people in service jobs (store clerks, waiters, bartenders, bank tellers and others) because you are Black?

$\begin{array}{llllllll}\text { How many times in the past year? } & 1 & 2 & 3 & 4 & 5 & 6\end{array}$

$\begin{array}{llllllll}\text { How many times in your entire life? } & 1 & 2 & 3 & 4 & 5 & 6\end{array}$ Not at All Extremely

$\begin{array}{llllllll}\text { How stressful was this for you? } & 1 & 2 & 3 & 4 & 5 & 6\end{array}$

5. How many times have you been treated unfairly by strangers because you are Black?

$\begin{array}{lllllll}\text { How many times in the past year? } & 1 & 2 & 3 & 4 & 5 & 6\end{array}$

$\begin{array}{llllllll}\text { How many times in your entire life? } & 1 & 2 & 3 & 4 & 5 & 6\end{array}$ Not at All Extremely

$\begin{array}{llllllll}\text { How stressful was this for you? } & 1 & 2 & 3 & 4 & 5 & 6\end{array}$

6. How many times have you been treated unfairly by people in helping jobs (doctors, nurses, psychiatrists, case workers, dentists, school counselors, therapists, social workers and others) because you are Black?

$\begin{array}{lllllll}\text { How many times in the past year? } & 1 & 2 & 3 & 4 & 5 & 6\end{array}$

$\begin{array}{llllllll}\text { How many times in your entire life? } & 1 & 2 & 3 & 4 & 5 & 6\end{array}$ Not at All Extremely

$\begin{array}{llllllll}\text { How stressful was this for you? } & 1 & 2 & 3 & 4 & 5 & 6\end{array}$

7. How many times bave you been treated unfairly by neighbors because you are Black?

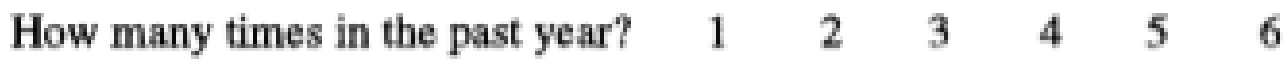

How many times in your entire life? $11 \quad 2 \quad \begin{array}{lllll}3 & 4 & 5 & 6\end{array}$ Not at All Extremely

$\begin{array}{llllllll}\text { How stressful was this for you? } & 1 & 2 & 3 & 4 & 5 & 6\end{array}$ 
8. How many times have you been treated unfairly by institutions (schools, universities, law firms, the police, the courts, the Department of Social Services, the Unemployment Office and others) because you are Black?

$\begin{array}{lllllll}\text { How many times in the past year? } & 1 & 2 & 3 & 4 & 5 & 6 \\ \text { How many times in your entire life? } & 1 & 2 & 3 & 4 & 5 & 6 \\ & \text { Not at All } & & & & \text { Extremely } \\ \text { How stressful was this for you? } & 1 & 2 & 3 & 4 & 5 & 6\end{array}$

9. How many times have you been treated unfairly by people that you thought were your friends because you are Black?

$\begin{array}{lllllll}\text { How many times in the past year? } & 1 & 2 & 3 & 4 & 5 & 6 \\ \text { How many times in your entire life? } & 1 & 2 & 3 & 4 & 5 & 6 \\ & \text { Not at All } & & & & \text { Extremely } \\ \text { How stressful was this for you? } & 1 & 2 & 3 & 4 & 5 & 6\end{array}$

10. How many times have you been accused or suspected of doing something wrong (such as stealing, cheating, not doing your share of the work, or breaking the law) because you are Black?

$\begin{array}{lllllll}\text { How many times in the past year? } & 1 & 2 & 3 & 4 & 5 & 6 \\ \text { How many times in your entire life? } & 1 & 2 & 3 & 4 & 5 & 6 \\ & \text { Not at All } & & & & \text { Extremely } \\ \text { How stressful was this for you? } & 1 & 2 & 3 & 4 & 5 & 6\end{array}$

11. How many times have people misunderstood your intentions and motives because you are Black?

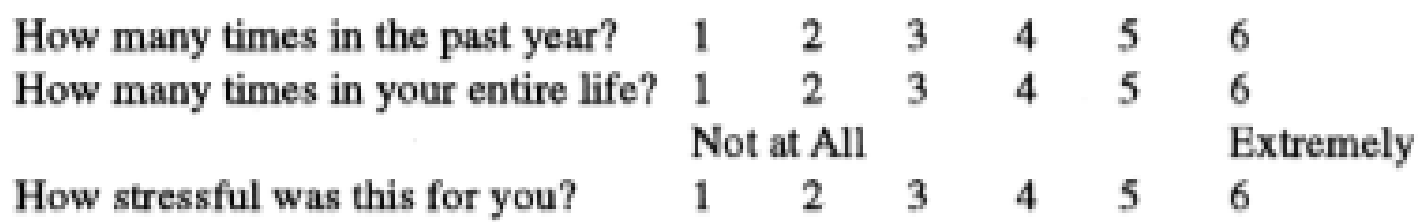

12. How many times did you want to tell someone off for being racist but didn' say anything?

$\begin{array}{lllllll}\text { How many times in the past year? } & 1 & 2 & 3 & 4 & 5 & 6\end{array}$

$\begin{array}{llllllll}\text { How many times in your entire life? } & 1 & 2 & 3 & 4 & 5 & 6\end{array}$ Not at All Extremely

$\begin{array}{lllllll}\text { How stressful was this for you? } & 1 & 2 & 3 & 4 & 5 & 6\end{array}$ 
13. How many times have you been really angry about something racist that was done to you?

\begin{tabular}{|c|c|c|c|c|c|c|}
\hline How many times in the past year? & 1 & 2 & 3 & 4 & 5 & 6 \\
\hline How many times in your entire life? & 1 & 2 & 3 & 4 & 5 & \\
\hline & \multicolumn{5}{|c|}{ Not at All } & Extremely \\
\hline How stressful was this for you? & 1 & 2 & 3 & 4 & 5 & 6 \\
\hline
\end{tabular}

14. How many times were you forced to take drastic steps (such as filing a grievance, filing a lawsuit, quitting your job, moving away, and other actions) to deal with some racist thing that was done to you?

\begin{tabular}{|c|c|c|c|c|c|c|}
\hline How many times in the past year? & 1 & 2 & 3 & 4 & 5 & 6 \\
\hline How many times in your entire life? & 1 & 2 & 3 & 4 & 5 & \\
\hline & \multicolumn{5}{|c|}{ Not at All } & Extremel \\
\hline How stressful was this for you? & 1 & 2 & 3 & 4 & 5 & 6 \\
\hline
\end{tabular}

15. How many times have you been called a racist name like $n \_$a coon, jungle bunny or other names?

$\begin{array}{lllllll}\text { How many times in the past year? } & 1 & 2 & 3 & 4 & 5 & 6 \\ \text { How many times in your entire life? } & 1 & 2 & 3 & 4 & 5 & 6 \\ & \text { Not at All } & & & & \text { Extremely } \\ \text { How stressful was this for you? } & 1 & 2 & 3 & 4 & 5 & 6\end{array}$

16. How many times have you gotten into an argument or a fight about something racist that was done to you or done to somebody else?

\begin{tabular}{|c|c|c|c|c|c|c|}
\hline \multirow{2}{*}{$\begin{array}{l}\text { How many times in the past year? } \\
\text { How many times in your entire life? }\end{array}$} & 1 & 2 & 3 & 4 & 5 & 6 \\
\hline & 1 & 2 & 3 & 4 & 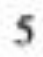 & \\
\hline & \multicolumn{5}{|c|}{ Not at All } & \\
\hline How stressful was this for you? & 1 & 2 & 3 & 4 & 5 & 6 \\
\hline
\end{tabular}

17. How many times have you been made fun of, picked on, pushed, shoved, hit, or threatened with harm because you are Black?

\begin{tabular}{|c|c|c|c|c|c|}
\hline How many times in the past year? & 1 & 3 & 4 & 5 & 6 \\
\hline How many times in your entire life? & 1 & 3 & 4 & 5 & 6 \\
\hline & \multicolumn{4}{|l|}{ Not at All } & Extremely \\
\hline How stressful was this for you? & 1 & 3 & 4 & 5 & 6 \\
\hline
\end{tabular}


18. How different would your life be now if you HAD NOT BEEN treated in a racist and unfair way

In the past year?

$\begin{array}{cccccc}\begin{array}{c}\text { Same } \\ \text { as now }\end{array} & \begin{array}{c}\text { A little } \\ \text { different }\end{array} & \begin{array}{c}\text { Different in } \\ \text { a few ways }\end{array} & \begin{array}{c}\text { Different in } \\ \text { a lot of ways }\end{array} & \begin{array}{c}\text { Different in } \\ \text { most ways }\end{array} & \begin{array}{c}\text { Totally } \\ \text { different }\end{array} \\ 1 & 2 & 3 & 4 & 5 & 6\end{array}$

In your entire life?

$\begin{array}{cccccc}\begin{array}{c}\text { Same } \\ \text { as now }\end{array} & \begin{array}{c}\text { A little } \\ \text { different }\end{array} & \begin{array}{c}\text { Different in } \\ \text { a few ways }\end{array} & \begin{array}{c}\text { Different in } \\ \text { a lot of ways }\end{array} & \begin{array}{c}\text { Different in } \\ \text { most ways }\end{array} & \begin{array}{c}\text { Totally } \\ \text { different }\end{array} \\ 1 & 2 & 3 & 4 & 5 & 6\end{array}$




\section{Appendix B}

\section{PARENTS' BELIEFS ABOUT CHILDREN'S EMOTIONS (PBACE, 2012)}

Instructions: These statements express some beliefs about children's emotional development. Please read each statement and write in the number that shows how much you agree with the statement. Put your response in the column titled "Answer." Please pick a child age (somewhere between the ages of 4 and 10) that you are familiar with, and respond to these statements for children of that age.

\begin{tabular}{|cccccc|}
\hline 1 & 2 & 3 & 4 & 5 & 6 \\
Strongly & Somewhat & Slightly & Slightly & Somewhat & Strongly \\
Disagree & Disagree & Disagree & Disagree & Agree & Agree \\
\hline
\end{tabular}

\section{Cost/Dangers of Positive \& Negative Emotions}

\section{Happiness}

1. Children may not focus on their commitments if they feel too much happiness.

2. When children are too happy, they can get out of control.

3. Too much joy can make it hard for a child to understand others.

4. Children who feel happiness strongly are likely to face a lot of trouble in life.

\section{Pride}

1. Children may not focus on their commitments if they feel too much pride.

2. When children are too prideful, they can get out of control.

3. Too much pride can make it hard for a child to understand others.

4. Children who feel pride strongly are likely to face a lot of trouble in life.

\section{Anger}

1. When children get angry, they create more problems for themselves.

2. Children's feelings can get hurt if they show too much anger.

3. Being angry can be a waste of time for children.

4. When children get angry, it can only lead to problems.

\section{Sadness}

1. When children get sad, they create more problems for themselves.

2. Children's feelings can get hurt if they show too much sadness.

3. Being sad can be a waste of time for children.

4. When children get sad, it can only lead to problems.

\section{Afraid}

1. When children become afraid, they create more problems for themselves.

2. Children's feelings can get hurt if they show too much fear. 
3. Being afraid can be a waste of time for children.

4. When children get afraid, it can only lead to problems.

\section{Value Positive \& Negative Emotions}

\section{Happiness}

1. It is useful for children to feel happy sometimes.

2. The experience of happiness can be a useful motivation for action.

3. Expressing happiness is a good way for a child to let his/her desires and opinions be known

4. Being happy can motivate children to change or fix something in their lives.

\section{Pride}

1. It is useful for children to feel prideful/proud sometimes.

2. The experience of pride can be a useful motivation for action.

3. Expressing pride is a good way for a child to let his/her desires and opinions be known

4. Being prideful/proud can motivate children to change or fix something in their lives.

\section{Anger}

1. It is useful for children to feel angry sometimes.

2. The experience of anger can be a useful motivation for action.

3. Expressing anger is a good way for a child to let his/her desires and opinions be known

4. Being angry can motivate children to change or fix something in their lives.

\section{Sadness}

1. It is useful for children to feel sad sometimes.

2. The experience of sadness can be a useful motivation for action.

3. Expressing sadness is a good way for a child to let his/her desires and opinions be known

4. Being sad can motivate children to change or fix something in their lives.

\section{Afraid}

1. It is useful for children to feel afraid sometimes.

2. The experience of fear can be a useful motivation for action.

3. Expressing fear is a good way for a child to let his/her desires and opinions be known

4. Being afraid can motivate children to change or fix something in their lives. 


\section{Appendix C}

\section{Emotion as a Child Questionnaire (EAC)}

For each item, please circle the number indicating how typical each response would be of you. When your child is sad, what do you do?

1. I don't notice my child's sadness

$$
\begin{gathered}
\text { Not at all } \\
\text { typical }
\end{gathered}
$$

2. Tell my child to cheer up

3. Buy something my child likes

1
1
1
1
1
1
1
1
1
1
1
1
1
1

4. Ask my child about it

5. Tell my child not to worry

6. Get tearful or cry

7. Give my child space to deal with it

8. Get sad myself

9. Give a discouraging look

10. I don't respond

11. Help my child deal with the issue

12. I get upset

13. I express disapproval verbally

14. Comfort my child

15. Say my child is silly or foolish

When your child is angry, what do you do?

Not at all

typical

1. Punish my child

$\begin{array}{ll}1 & 2 \\ 1 & 2 \\ 1 & 2 \\ 1 & 2 \\ 1 & 2 \\ 1 & 2 \\ 1 & 2 \\ 1 & 2 \\ 1 & 2 \\ 1 & 2 \\ 1 & 2 \\ 1 & 2 \\ 1 & 2 \\ 1 & 2 \\ 1 & \end{array}$

2
2
2
2
2
2
2
2
2
2
2
2
2
2
2

$$
\begin{gathered}
\text { Somewhat } \\
\text { typical }
\end{gathered}
$$

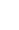

2

2

2

2

2

2

2

2

2

2

2

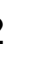

2

2

$\begin{array}{cccc} & \begin{array}{c}\text { Somewhat } \\ \text { typical }\end{array} & & \begin{array}{c}\text { Very } \\ \text { typical }\end{array} \\ 2 & 3 & 4 & 5 \\ 2 & 3 & 4 & 5 \\ 2 & 3 & 4 & 5 \\ 2 & 3 & 4 & 5 \\ 2 & 3 & 4 & 5 \\ 2 & 3 & 4 & 5 \\ 2 & 3 & 4 & 5 \\ 2 & 3 & 4 & 5 \\ 2 & 3 & 4 & 5 \\ 2 & 3 & 4 & 5 \\ 2 & 3 & 4 & 5 \\ 2 & 3 & 4 & 5 \\ 2 & 3 & 4 & 5 \\ 2 & 3 & 4 & 5 \\ 2 & 3 & 4 & 5\end{array}$


Reward: 3, 9, 12

Punish: 1, 5, 10

Override: 4, 7, 14

Neglect: 2, 11, 13

Magnify: 6, 8, 15

When your child is afraid, what do you do?

1. Tell my child not to be frightened

$$
\begin{gathered}
\text { Not at all } \\
\text { typical }
\end{gathered}
$$

2. Hold my child

1

3. I don't respond

4. Tell my child to grow up

5. Punish my child

6. Get scared myself

7. I don't notice my child's fear

8. Tell my child not to be a "fraidy cat"

9. Help my child deal with the problem

10. Tell my child not to worry

11. Become worried myself

12. Ask my child what is wrong

13. Distract my child

14. Give my child space to deal with it

15. Say I am worried, too

1
1
1
1
1
1
1
1
1
1

Somewhat
typical

Very

3

typical

2

Reward: 2, 9, 12

Punish: 4, 5, 8

Override: 1, 10, 13

Neglect: 3, 7, 14

Magnify: 6, 11, 15

When your child is happy, what do you do?
Not at all typical

Somewhat

Very typical

typical

1. Usually don't notice

1

2. Change the subject

12

3. Tell them that there are other things that are more important 
4. Am interested in why they are happy

2

3

4

5. Notice their feelings and quickly move on to something else

\section{2}

6. Become very happy myself

7. Usually not around

8. Join in their happiness

9. Tells them to keep it to themselves

10. Don't ask about it

11. Listen to them

12. Say I am happy, too

13. Tell them to settle down

1

3

$$
4
$$

4

14. Encourage them to share their happiness

2

4

5

15. Show that I don't like them being happy

When your child is prideful/proud, what do you do?

1. Usually don't notice

Not at all

typical

Somewhat
typical

Very

typical

2. Change the subject

3. Tell them that there are other things that are more important

4. Am interested in why they are proud

5. Notice their feelings and quickly move on to something else

6. Become very prideful/proud myself 1

7. Usually not around

8. Join in their pridefulness/proudness

9. Tells them to keep it to themselves

10. Don't ask about it

3

3

11. Listen to them

12. Say I am proud, too

3

13. Tell them to settle down

3

3

14. Encourage them to share their proudness

15. Show that I don't like them being 


\section{Appendix D}

\section{$\underline{\text { Racial Socialization Scale }}$}

The following are messages and activities that parents may or may not share or engage in with their children. Please rate on the scale given below, the frequency with which you have given your child these messages or participated in these activities.

$$
0=\text { Never } \quad 1=\text { Once or twice } \quad 2=\text { More than twice }
$$

\section{HOW OFTEN HAVE YOU:}

1. Told your child that Blacks and Whites should try to understand each other so they can get along.

2. Told your child that learning about Black history is not that important.

3. Told your child that some people try to keep Black people from being successful.

4. Been involved in activities that focus on things important to Black people.

5. Bought your child Black toys or games.

6. Told your child that some people think they are better than him/ her because of their race.

7. Told your child it is best to act like Whites.

8. Gone with your child to Black cultural events (i.e. plays, movies, concerts, museums).

9. Told your child that because of opportunities today, hardworking Blacks have the same chance to succeed as anyone else.

10. Told your child that s/he is somebody special, no matter what anyone says.

11. Told your child that s/he should try to have friends of all different races.

12. Told your child that Blacks have to work twice as hard as Whites to get ahead.

13. Told your child to be proud of who s/he is.

14. Told your child that skin color does not define who s/he is.

15. Gone with your child to cultural events involving other races and cultures (i.e. plays, movies, concerts, museums).

16. Told your child that being Black is nothing to be proud of.

17. Talked to your child about Black history.

18. Told your child s/he can be whatever s/he wants to be.

19. Went with your child to organizational meetings that dealt with Black issues.

20. Told your child that $\mathrm{s} / \mathrm{he}$ should be proud to be Black.

21. Told your child that s/he can learn things from people of different races.

22. Told your child White businesses are more reliable than Black businesses.

23. Told your child that some people may dislike him/ her because of the color of his/her skin.

24. Told your child Blacks are not as smart as people of other races.

25. Told your child never to be ashamed of his/ her Black features (i.e. hair texture, skin color, lip shape, etc.).

26. Bought your child books about Black people. 


\section{$\underline{\text { Appendix E }}$}

\section{Satisfaction with Life Scale}

Below are five statements that you may agree or disagree with. Using the $1-7$ scale below, indicate your agreement with each item by placing the appropriate number on the line preceding that item. Please be open and honest in your responding.

- 7 - Strongly agree

- 6 - Agree

- 5 - Slightly agree

- 4 - Neither agree nor disagree

- 3 - Slightly disagree

- 2 - Disagree

- 1 - Strongly disagree

In most ways my life is close to my ideal.

The conditions of my life are excellent.

I am satisfied with my life.

So far I have gotten the important things I want in life.

If I could live my life over, I would change almost nothing. 


\section{$\underline{\text { Appendix F }}$}

\section{$\underline{\text { Anger Expression Inventory }}$}

A number of statements that people have used to describe themselves are given below.

Read the statements below and indicate how you generally react or behave when you feel angry or furious by placing the appropriate number next to each item.

$1=$ Almost never

$2=$ Sometimes

$3=$ Often

$4=$ Almost always

_. I express my anger

2. If someone is annoying, I am apt to tell him or her

3. I lose my temper

4. I make sarcastic remarks to others

5. I do things like slam doors

6. I argue with others

7. I strike out at whatever is infuriating

8. I say nasty things 


\section{$\underline{\text { Appendix G }}$}

\section{Center for Epidemiologic Studies Depression Scale (CES-D)}

Below is a list of the ways you might have felt or behaved. Please tell me how often you have felt this way during the past week.

\section{Week}

\section{During the Past}

\begin{tabular}{|c|c|c|c|}
\hline $\begin{array}{l}\text { Rarely or none of } \\
\text { the time (less than } \\
1 \text { day) }\end{array}$ & $\begin{array}{c}\text { Some or a } \\
\text { little of the } \\
\text { time (1-2 } \\
\text { days) }\end{array}$ & $\begin{array}{c}\text { Occasionally or a } \\
\text { moderate amount of time } \\
\text { (3-4 days) }\end{array}$ & $\begin{array}{l}\text { Most or all of } \\
\text { the time (5-7 } \\
\text { days) }\end{array}$ \\
\hline
\end{tabular}

1. I was bothered by things that usually don't bother me.

2. I did not feel like eating; my appetite was poor.

3. I felt that I could not shake off the blues even with help from my family or friends.

4. I felt I was just as good as other people.

5. I had trouble keeping my mind on what I was doing.

6. I felt depressed.

7. I felt that everything I did was an effort.

8. I felt hopeful about the future.

9. I thought my life had been a failure.

10. I felt fearful.

11. My sleep was restless.

12. I was happy.

13. I talked less than usual.

14. I felt Ionely.

15. People were unfriendly.

16. I enjoyed life.

17. I had crying spells.

18. I felt sad.

19. I felt that people dislike me.

20. I could not get "going."

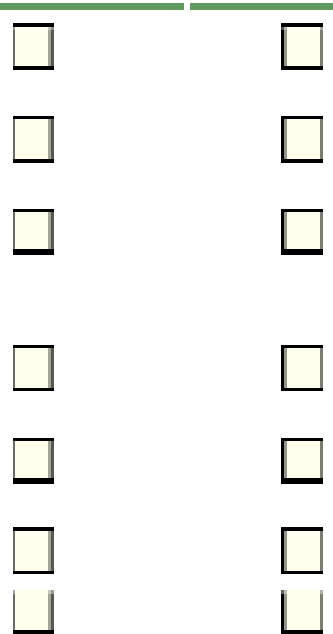

$\begin{array}{ll}\square & \square \\ \square & \square \\ \square & \square\end{array}$

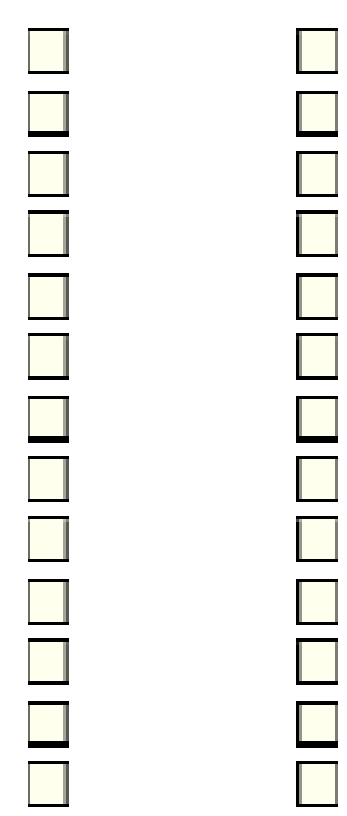




\section{Appendix H}

Unstandardized Estimates and Standard Errors of Multigroup Structural Model Testing Associations among Variables of Interest

\begin{tabular}{|c|c|c|c|c|c|c|c|c|}
\hline \multirow{3}{*}{ Path of Regressions } & \multicolumn{4}{|c|}{$\underline{\text { Negative Emotions }}$} & \multicolumn{4}{|c|}{$\underline{\text { Positive Emotions }}$} \\
\hline & \multicolumn{2}{|c|}{$\underline{\text { Mothers }}$} & \multicolumn{2}{|c|}{$\underline{\text { Fathers }}$} & \multicolumn{2}{|c|}{ Mothers } & \multicolumn{2}{|c|}{$\underline{\text { Fathers }}$} \\
\hline & $\underline{B}$ & $\underline{S E}$ & $\underline{B}$ & $\underline{S E}$ & $\underline{B}$ & $\underline{S E}$ & $\underline{B}$ & $\underline{S E}$ \\
\hline Discrim $\rightarrow$ Value Emotions & $.28^{* * * *}$ & .05 & $.32^{* * *}$ & .04 & -.002 & .05 & .05 & .05 \\
\hline Discrim $\rightarrow$ Emotions Dangerous & $.43^{* * *}$ & .06 & $.41^{* * * *}$ & .05 & $.63^{* * *}$ & .06 & $.59^{* * *}$ & .05 \\
\hline Discrim $\rightarrow$ Unsupportive ES & $.46^{* * * *}$ & .05 & $.57^{* * * *}$ & .04 & $.35^{* * *}$ & .04 & $.39^{* * * *}$ & .04 \\
\hline Discrim $\rightarrow$ Supportive ES & .01 & .01 & .04 & .02 & -.02 & .05 & -.01 & .04 \\
\hline Discrim $\rightarrow$ Racial Soc. & -.03 & .03 & $-.09^{* *}$ & .03 & .04 & .02 & -.04 & .03 \\
\hline Value Emotions $\rightarrow$ Unsupportive ES & .07 & .05 & $.10^{*}$ & .05 & $-.20^{* * * *}$ & .05 & $-.11^{*}$ & .05 \\
\hline Value Emotions $\rightarrow$ Supportive & -.003 & .01 & -.01 & .01 & $.75^{* * * *}$ & .06 & $.60^{* * * *}$ & .05 \\
\hline Value Emotions $\rightarrow$ Race Soc. & $.11^{* *}$ & .03 & $.14^{* * * *}$ & .04 & $.24^{* * * *}$ & .04 & $.22^{* * * *}$ & .03 \\
\hline Emotions Dangerous $\rightarrow$ Unsupportive & $.32^{* * *}$ & .05 & $.22^{* * *}$ & .05 & $.54^{* * *}$ & .04 & $.58^{* * *}$ & .05 \\
\hline Emotions Dangerous $\rightarrow$ Supportive & .03 & .05 & .05 & .03 & -.07 & .05 & .02 & .04 \\
\hline Emotions Dangerous $\rightarrow$ Race Soc. & -.03 & .03 & .04 & .03 & $-.08^{* * * *}$ & .02 & -.01 & .03 \\
\hline
\end{tabular}

Note . Race Soc. $=$ Racial socialization. ES = Emotion socialization. ${ }^{*} p<.05,{ }^{* *} p<.01,{ }^{* * *} p<.001$. 